\title{
Nonlinear flow model for well production in an underground formation
}

\author{
J. C. Guo and R. S. Nie \\ State Key Laboratory of Oil \& Gas Reservoir Geology and Exploitation, Southwest Petroleum University, \\ Chengdu 0086.610500, Sichuan Province, China
}

Correspondence to: R. S. Nie (nierenshi2000@126.com)

Received: 20 January 2012 - Revised: 22 March 2013 - Accepted: 18 April 2013 - Published: 17 May 2013

\begin{abstract}
Fluid flow in underground formations is a nonlinear process. In this article we modelled the nonlinear transient flow behaviour of well production in an underground formation. Based on Darcy's law and material balance equations, we used quadratic pressure gradients to deduce diffusion equations and discuss the origins of nonlinear flow issues. By introducing an effective-well-radius approach that considers skin factor, we established a nonlinear flow model for both gas and liquid (oil or water). The liquid flow model was solved using a semi-analytical method, while the gas flow model was solved using numerical simulations because the diffusion equation of gas flow is a stealth function of pressure. For liquid flow, a series of standard log-log type curves of pressure transients were plotted and nonlinear transient flow characteristics were analyzed. Qualitative and quantitative analyses were used to compare the solutions of the linear and nonlinear models. The effect of nonlinearity upon pressure transients should not be ignored. For gas flow, pressure transients were simulated and compared with oil flow under the same formation and well conditions, resulting in the conclusion that, under the same volume rate production, oil wells demand larger pressure drops than gas wells. Comparisons between theoretical data and field data show that nonlinear models will describe fluid flow in underground formations realistically and accurately.
\end{abstract}

\section{Introduction}

Among the many nonlinear geophysical processes, transient fluid flow through porous media is of particular interest (Cao et al., 2004; Finjord, 1990; Finjord and Aadnoy, 1989; Giachetti and Maroscia, 2008; Liang et al., 2001). This process, which is of practical importance, is governed by the diffu- sivity equation, an equation describing the nonlinearities resulting from the dependence of fluid and medium properties on pressure. When porosity, permeability and fluid density depend exponentially on pressure, the diffusivity equation reduces to a diffusion equation containing a squared gradient term. Many published articles have described analytical solutions for this equation through variable modifications (Chakrabarty et al., 1993a, b; Jelmert and Vik, 1996; Odeh and Babu, 1998; Wang and Dusseault, 1991), which are special cases of the Hopf-Cole transformation (Marshall, 2009). Applications in dual-porosity (Bai et al., 1994; Bai and Roegiers, 1994) and fractal (Tong and Wang, 2005) media have also been described. Pressure transients are graphic plots of theoretical solutions for diffusion equations under specific initial and boundary conditions for the well-test model that represents a reservoir-well system (Chaudhry, 2004). Pressure transients were plotted according to these analytical solutions and were used in the interpretation of well-test transients (Braeuning et al., 1998). This research showed that the quadratic pressure gradient term influenced the pressure transient solutions. If the nonlinear term is ignored, significant errors in predicted pressures during certain live oil and low permeability reservoir operations, such as hydraulic fracturing, large-drawdown flows, slug testing, drill-stem testing and large-pressure pulse testing will occur. Even though the importance of nonlinearity has been heavily emphasised, no application of modern well-test interpretation (Onur et al., 2003) on field data has been found; in fact, a standard set of log-log type curves for modern well-test interpretation has not been developed, except for type curves for nonlinear spherical flow (Nie and Ding, 2010). In addition, there has not been any research or discussion on the effects of quadratic pressure gradients on gas flow. 
Therefore, the main tasks of this article is to (1) deduce the nonlinear governing equations with the quadratic pressure gradient term for both liquid and gas flow in porous media and discuss the origins of the nonlinear flow issue; (2) establish and solve a nonlinear flow model for well production; (3) plot a series of standard type curves for wellbore pressure-transient analysis for liquid flow in an underground formation; (4) analyze the nonlinear flow characteristics of liquid flow using type curves; (5) make qualitative and quantitative comparisons of pressure and its derivative transients between nonlinear and linear liquid flow models; (6) simulate wellbore pressure transients for nonlinear gas flow using numerical simulations and compare these pressure transients with nonlinear oil flow under the same formation and well conditions; and (7) match theoretical data from nonlinear and linear models against field data to assess the differences between actual and theoretical applications. The results of this research suggest the use of a nonlinear flow model in actual studies.

Compared with previous publications, such as Cao et al. (2004), Chakrabarty et al. (1993b), Marshall (2009), this research highlights (1) newly considered use of real parameters for wells with skin factor in nonlinear flow models; (2) application of modern standard type curves to intuitively observe nonlinear transient flow behaviour; (3) recognition of flow regimes from type curves, including recognition of different external boundary responses; (4) thorough analysis of parameter sensitivity to type curves; (5) use of quantitative methods of "DV" and "RDV" to describe solution differences between nonlinear and linear models; (6) establishment of numerical modelling of nonlinear gas flow and simulation and comparison of nonlinear gas and oil flow pressure transients; and (7) consideration of real world applications through comparisons of theoretical data and field data.

\section{Nonlinear governing equation}

\subsection{Liquid flow}

For vertical well production in a homogeneous formation, flow in a vertical plane is not significant and a radial cylindrical coordinate system without a $\mathrm{z}$ coordinate can be employed to describe the diffusion equation:

$\frac{1}{r} \frac{\partial}{\partial r}\left(r \frac{\partial p}{\partial r}\right)+C_{\rho}\left(\frac{\partial p}{\partial r}\right)^{2}=\frac{10 \mu \varphi C_{\mathrm{t}}}{k_{\mathrm{h}}} \frac{\partial p}{\partial t}$,

where $p$ is pressure, MPa; $r$ is radial cylindrical coordinate, $\mathrm{cm} ; t$ is time, $\mathrm{s} ; \varphi$ is rock porosity, fraction; $k$ is radial permeability, $\mu \mathrm{m}^{2} ; \mu$ is viscosity, $\mathrm{mPas} ; C_{\mathrm{t}}$ is total compressibility of rock and liquid, $\mathrm{MPa}^{-1} ; C_{\rho}$ is liquid compressibility, $\mathrm{MPa}^{-1}$.

The governing partial differential equation is nonlinear because of the quadratic pressure gradient term (i.e. the second power of the pressure gradient in Eq. 1).
The appendix deduces the diffusivity equation containing the quadratic gradient term when porosity and fluid density depend exponentially on pressure (Marshall, 2009; Nie and Ding, 2010):

$\rho=\rho_{0} e^{C_{\rho}\left(p-p_{0}\right)}$,

$\varphi=\varphi_{0} e^{C_{\mathrm{f}}\left(p-p_{0}\right)}$,

where $\rho$ is density, $\mathrm{g} \mathrm{cm}^{-3} ; C_{\mathrm{f}}$ is rock compressibility, $\mathrm{MPa}^{-1} ; \rho_{0}, \varphi_{0}, p_{0}$ are reference values, which are usually used in standard conditions.

The function $e^{x}$ using Maclaurin series expansion can be written by

$e^{x}=1+x+x^{2} / 2+\ldots+x^{n} / n !+\ldots$.

If we use Maclaurin series expansion for Eqs. (2) and (3) and neglect second and higher order items, Eqs. (5) and (6) can replace Eqs. (2) and (3), respectively

$\rho=\rho_{0}\left[1+C_{\rho}\left(p-p_{0}\right)\right]$

$\varphi=\varphi_{0}\left[1+C_{\mathrm{f}}\left(p-p_{0}\right)\right]$.

Appearance of the quadratic pressure gradient term is due to a lack of simplification in the state equations (Eqs. 2 and 3) when deducing the diffusion equation. If we use Eqs. 5 and (6), we obtain the conventional linear flow equation without the quadratic pressure gradient term.

Therefore, the linear flow equation is an approximation and simplification of the nonlinear flow equation which includes the quadratic pressure gradient term. In fact, flow of liquid in porous media is a complex nonlinear process and the nonlinear flow law is equal to the flow law of liquid in porous media.

\subsection{Gas flow}

Gas flow in porous media is different from that of liquid due to a different state equation for fluid (Nie et al., 2012a):

$p V=Z n R T$,

where $V$ is gas volume, $\mathrm{cm}^{3} ; Z$ is a compressibility factor, fraction; $n$ is number of gas moles, mol; $R$ is a universal gas constant, $\mathrm{J}(\mathrm{mol} \mathrm{K})^{-1} ; T$ is gas temperature, $\mathrm{K}$.

Gas volume is a function of mass and density:

$V=\frac{m}{\rho}$,

where $m$ is gas mass, $\mathrm{g} ; \rho$ is density, $\mathrm{g} \mathrm{cm}^{-3}$. 
Number of gas moles is a function of mass and average molecular weight:

$n=\frac{m}{M}$,

where $M$ is average molecular weight of gas, $\mathrm{g} \mathrm{mol}^{-1}$.

Substitute Eqs. (8) and (9) into Eq. (7):

$\rho=\frac{p M}{Z R T}$

We consider isothermal equations and Darcy's flow and substitute Eq. (10) into Eq. (A3):

$$
\begin{aligned}
& \frac{\partial}{\partial x}\left(\frac{p M}{Z R T} \frac{k_{x}}{\mu} \frac{\partial p}{\partial x}\right)+\frac{\partial}{\partial y}\left(\frac{p M}{Z R T} \frac{k_{y}}{\mu} \frac{\partial p}{\partial y}\right)+\frac{\partial}{\partial z}\left(\frac{p M}{Z R T} \frac{k_{z}}{\mu} \frac{\partial p}{\partial z}\right) \\
& =10 \frac{\partial}{\partial t}\left(\frac{p M}{Z R T} \varphi\right),
\end{aligned}
$$

where $x, y$, and $z$ are Cartesian coordinates; $k_{x}$ is permeability in the $x$ direction, $\mu \mathrm{m}^{2} ; k_{y}$ is permeability in the $y$ direction, $\mu \mathrm{m}^{2} ; k_{z}$ is permeability in the $z$ direction, $\mu \mathrm{m}^{2}$.

We assume an elastic and slightly compressible rock and isotropic and constant permeability in both the horizontal and vertical plane:

$$
\begin{aligned}
& \frac{\partial}{\partial x}\left(\frac{p}{\mu Z} \frac{\partial p}{\partial x}\right)+\frac{\partial}{\partial y}\left(\frac{p}{\mu Z} \frac{\partial p}{\partial y}\right)+\frac{k_{z}}{k_{\mathrm{h}}} \frac{\partial}{\partial z}\left(\frac{p}{\mu Z} \frac{\partial p}{\partial z}\right) \\
& =\frac{10}{k_{\mathrm{h}}} \frac{\partial}{\partial t}\left(\frac{p}{Z} \varphi\right),
\end{aligned}
$$

where $k_{\mathrm{h}}$ is horizontal permeability that is equal to $k_{x}$ and $k_{y}$ is isotropic formation in the horizontal plane, $\mu \mathrm{m}^{2}$.

The partial differential terms in the left of Eq. (12) are expressed by

$\frac{\partial}{\partial j}\left(\frac{p}{\mu Z} \frac{\partial p}{\partial j}\right)=\frac{1}{2} \frac{1}{\mu Z}\left[\frac{\partial^{2} p^{2}}{\partial j^{2}}-\frac{\partial \ln (\mu Z)}{\partial p^{2}}\left(\frac{\partial p^{2}}{\partial j}\right)^{2}\right]$,

$(j=x, y, z)$.

The partial differential term in the right of Eq. (12) is expressed by

$$
\begin{aligned}
& \frac{\partial}{\partial t}\left(\frac{p}{Z} \varphi\right)=\frac{p}{Z} \frac{\partial \varphi}{\partial t}+\varphi \frac{\partial}{\partial t}\left(\frac{p}{Z}\right)=\frac{\varphi C_{\mathrm{f}}}{2 Z} \frac{\partial p^{2}}{\partial t} \\
& +\frac{\varphi}{2 Z}\left(\frac{1}{p}-\frac{1}{Z} \frac{\partial Z}{\partial p}\right) \frac{\partial p^{2}}{\partial t} .
\end{aligned}
$$

Gas isothermal compressibility is a function of pressure and compressibility factor:

$C_{\mathrm{g}}=\frac{1}{p}-\frac{1}{Z} \frac{\partial Z}{\partial p}$.
Substitute Eqs. (13-15) into Eq. (12):

$$
\begin{aligned}
& \frac{\partial^{2} p^{2}}{\partial x^{2}}+\frac{\partial^{2} p^{2}}{\partial y^{2}}+\frac{k_{z}}{k_{\mathrm{h}}} \frac{\partial^{2} p^{2}}{\partial z^{2}}-\frac{\partial \ln (\mu Z)}{\partial p^{2}}\left[\left(\frac{\partial p^{2}}{\partial x}\right)^{2}+\left(\frac{\partial p^{2}}{\partial y}\right)^{2}\right. \\
& \left.+\left(\frac{\partial p^{2}}{\partial z}\right)^{2}\right]=\frac{10 \varphi \mu C_{\mathrm{t}}}{k_{\mathrm{h}}} \frac{\partial p^{2}}{\partial t}
\end{aligned}
$$

$C_{\mathrm{t}}=C_{\mathrm{g}}+C_{\mathrm{f}}$,

where $C_{\mathrm{g}}$ is gas compressibility, $\mathrm{MPa}^{-1} ; C_{\mathrm{t}}$ is total compressibility of rock and gas, $\mathrm{MPa}^{-1}$.

Equation (16) is a diffusion equation containing the quadratic derivative term of pressure square in Cartesian coordinates for gas flow in a homogeneous formation. Equation (16) shows that flow of gas in porous media is a nonlinear process. Compared with the governing differential equation of liquid (Eq. 1), Eq. (16) shows a more complex nonlinear properties. It is difficult to solve this diffusion equation because the term of $\partial \ln (\mu Z) / \partial p^{2}$ is a stealth function of pressure and not a constant. Usually the pseudo-pressure (or "potential") function (Ertekin and Sung, 1989; King and Ertekin, 1988; Nie et al., 2012a) can be used to describe the governing equation of gas flow:

$\psi=\int_{p_{\mathrm{sc}}}^{p} \frac{1}{\mu Z} \mathrm{~d} p^{2}=2 \int_{p_{\mathrm{sc}}}^{p} \frac{p}{\mu Z} \mathrm{~d} p$,

where $\psi$ is gas pseudo-pressure, $\mathrm{MPa}^{2}\left(\mathrm{mPas}^{-1}\right)^{-1} ; p_{\mathrm{sc}}$ is pressure at standard conditions, MPa.

Derivatives of pseudo-pressure to coordinates can be expressed by

$\frac{\partial \psi}{\partial j}=\frac{2 p}{\mu Z} \frac{\partial p}{\partial j},(j=x, y, z)$.

Derivative of pseudo-pressure to time can be expressed by

$\frac{\partial \psi}{\partial t}=\frac{2 p}{\mu Z} \frac{\partial p}{\partial t}$.

Substitute Eq. (20) into the right of Eq. (12):

$$
\begin{aligned}
& \frac{10}{k_{\mathrm{h}}} \frac{\partial}{\partial t}\left(\frac{p}{Z} \varphi\right)=\frac{10}{k_{\mathrm{h}}} \frac{p}{Z} \varphi\left[C_{\mathrm{f}}+\left(1-\frac{p}{Z} \frac{\partial Z}{\partial p}\right)\right] \frac{\partial p}{\partial t} \\
& =\frac{10}{k_{\mathrm{h}}} \frac{\varphi \mu C_{\mathrm{t}}}{2} \frac{\partial \psi}{\partial t} .
\end{aligned}
$$

Substitute Eq. (19) into the left of Eq. (12):

$$
\begin{aligned}
& \frac{\partial}{\partial x}\left(\frac{p}{\mu Z} \frac{\partial p}{\partial x}\right)+\frac{\partial}{\partial y}\left(\frac{p}{\mu Z} \frac{\partial p}{\partial y}\right)+\frac{k_{z}}{k_{\mathrm{h}}} \frac{\partial}{\partial z}\left(\frac{p}{\mu Z} \frac{\partial p}{\partial z}\right) \\
& =\frac{1}{2}\left(\frac{\partial^{2} \psi}{\partial x^{2}}+\frac{\partial^{2} \psi}{\partial y^{2}}+\frac{k_{z}}{k_{\mathrm{h}}} \frac{\partial^{2} \psi}{\partial z^{2}}\right) .
\end{aligned}
$$


Then, the diffusion equation expressed by gas pseudopressure can be obtained by

$\frac{\partial^{2} \psi}{\partial x^{2}}+\frac{\partial^{2} \psi}{\partial y^{2}}+\frac{k_{z}}{k_{\mathrm{h}}} \frac{\partial^{2} \psi}{\partial z^{2}}=\frac{10 \varphi \mu C_{\mathrm{t}}}{k_{\mathrm{h}}} \frac{\partial \psi}{\partial t}$.

Equation (23) is a diffusion equation without a quadratic derivative term. According to Eqs. (15) and (17), total compressibility of rock and gas is a stealth function of pressure because gas compressibility is a stealth function of pressure. In addition, gas viscosity is also a stealth function of pressure. Therefore, Eq. (23) is still a nonlinear equation. This nonlinear equation is very difficult to solve using analytical methods; however, a numerical approach will be implemented.

\section{Description of the nonlinear flow model}

\subsection{Physical model}

Physical model assumptions:

1. Single vertical well production at a constant rate in a homogeneous and isotropic formation saturated by a single-phase fluid (gas, oil or water) and the external boundary of formation may be infinite, closed or of constant pressure.

2. Slightly compressible rock and liquid (oil or water) with a constant compressibility are considered, while the compressibility of gas changes with depletion of pressure.

3. Isothermal equations and Darcy's flow, ignoring the impact of gravity and capillary forces.

4. Wellbore storage effect is considered when the well is opened, while fluid stored in the wellbore starts to flow and when fluid in formation does not.

5. Skin effect is considered near the wellbore where the formation could be damaged by drilling and completion operations (there could be an additional pressure drop during production, with the "skin" being a reflection of additional pressure drop).

6. At time $t=0$, pressure is uniformly distributed in formation, equal to initial pressure $\left(p_{\mathrm{i}}\right)$.

\subsection{Mathematical model}

For the convenience of well-test analysis, the mathematical model was established using a set of applied engineering units.

\subsubsection{Liquid flow in a formation}

\section{(1) Establishment of mathematical model}

The governing differential equation in a radial cylindrical system

$\frac{1}{r} \frac{\partial}{\partial r}\left(r \frac{\partial p}{\partial r}\right)+C_{\rho}\left(\frac{\partial p}{\partial r}\right)^{2}=\frac{\mu \varphi C_{\mathrm{t}}}{3.6 k_{\mathrm{h}}} \frac{\partial p}{\partial t}$,

where $C_{\rho}$ is liquid compressibility, $\mathrm{MPa}^{-1} ; C_{\mathrm{t}}$ is total compressibility of rock and liquid, $\mathrm{MPa}^{-1} ; k_{\mathrm{h}}$ is radial formation permeability, $\mu \mathrm{m}^{2} ; p$ is formation pressure, MPa; $r$ is radial radius from the centre of wellbore, $\mathrm{m} ; t$ is well production time, $\mathrm{h}$.

Initial condition

$\left.p\right|_{t=0}=p_{\mathrm{i}}$,

where $p_{\mathrm{i}}$ is initial formation pressure, MPa.

Well production condition based on effective radius

$\left.\frac{k h}{\mu}\left(r \frac{\partial p}{\partial r}\right)\right|_{r=r_{\mathrm{wa}}}=1.842 \times 10^{-3} q B+0.04421 C_{\mathrm{s}} \frac{\mathrm{d} p_{\mathrm{w}}}{\partial t}$,

where $B$ is oil volume factor, dimensionless; $C_{\mathrm{s}}$ is wellbore storage coefficient, $\mathrm{m}^{3} \mathrm{MPa}^{-1} ; p_{\mathrm{w}}$ is wellbore pressure, MPa; $q$ is well rate at wellhead, $\mathrm{m}^{3} \mathrm{~d}^{-1} ; r_{\text {wa }}$ is effective wellbore radius, $\mathrm{m}$.

The effective wellbore radius $r_{\mathrm{wa}}$ is defined as (Agarwal et al., 1970; Chaudhry, 2004)

$r_{\mathrm{wa}}=r_{\mathrm{w}} e^{-S}$,

where $r_{\mathrm{w}}$ is real wellbore radius, $\mathrm{m}$; $S$ is skin factor, dimensionless.

External boundary conditions:

$\left.\lim p\right|_{r_{\mathrm{e}} \rightarrow \infty}=p_{\mathrm{i}}$ (infinite) ,

$\left.p\right|_{r=r_{\mathrm{e}}}=p_{\mathrm{i}}$ (constant pressure),

$\left.\frac{\partial p}{\partial r}\right|_{r=r_{\mathrm{e}}}=0$ (closed)

where $r_{\mathrm{e}}$ is external boundary radius, $\mathrm{m}$.

The following dimensionless definitions are introduced to solve the mathematical model:

Dimensionless pressure:

$p_{\mathrm{D}}=k h\left(p_{\mathrm{i}}-p\right) /\left(1.842 \times 10^{-3} q B \mu\right)$.

Skin factor: $S=k h \Delta p_{\mathrm{s}} /\left(1.842 \times 10^{-3} q B \mu\right)$,

$\Delta p_{\mathrm{s}}$ is additional pressure drop near wellbore. 
Dimensionless radius based on effective well radius:

$r_{\mathrm{D}}=r /\left(r_{\mathrm{w}} e^{-S}\right)$.

Dimensionless radius of external boundary:

$r_{e \mathrm{D}}=r_{e} /\left(r_{\mathrm{w}} e^{-S}\right)$.

$\frac{\partial^{2} p_{\mathrm{D}}}{\partial r_{\mathrm{D}}^{2}}=\frac{1}{\beta} \frac{1}{(\xi+1)^{2}}\left(\frac{\partial \xi}{\partial r_{\mathrm{D}}}\right)^{2}-\frac{1}{\beta} \frac{1}{(\xi+1)}\left(\frac{\partial^{2} \xi}{\partial r_{\mathrm{D}}^{2}}\right)$,

Dimensionless wellbore storage coefficient:

$C_{\mathrm{D}}=C_{\mathrm{s}} /\left(6.2832 \varphi C_{\mathrm{t}} h r_{\mathrm{w}}^{2}\right)$.

Dimensionless time: $t_{\mathrm{D}}=3.6 \mathrm{kt} /\left(\varphi \mu C_{\mathrm{t}} r_{\mathrm{w}}^{2}\right)$.

$\left(\frac{\partial p_{\mathrm{D}}}{\partial r_{\mathrm{D}}}\right)^{2}=\frac{1}{\beta^{2}} \frac{1}{(\xi+1)^{2}}\left(\frac{\partial \xi}{\partial r_{\mathrm{D}}}\right)^{2}$,

Dimensionless coefficient of nonlinear term:

$\beta=\left(1.842 \times 10^{-3} q B \mu C_{\rho}\right) /(k h)$.

The dimensionless mathematical model is as follows:

Governing differential equation in a radial cylindrical system equals

$\frac{\partial^{2} p_{\mathrm{D}}}{\partial r_{\mathrm{D}}^{2}}+\frac{1}{r_{\mathrm{D}}} \frac{\partial p_{\mathrm{D}}}{\partial r_{\mathrm{D}}}-\beta\left(\frac{\partial p_{\mathrm{D}}}{\partial r_{\mathrm{D}}}\right)^{2}=\frac{1}{\left(C_{\mathrm{D}} e^{2 S}\right)} \frac{\partial p_{\mathrm{D}}}{\partial T_{\mathrm{D}}}$,

$T_{\mathrm{D}}=t_{\mathrm{D}} / C_{\mathrm{D}}$

Initial condition:

$\left.p_{\mathrm{D}}\right|_{T_{\mathrm{D}}=0}=0$.

Well production condition:

$\frac{\partial p_{\mathrm{D}}}{\partial T_{\mathrm{D}}}=-\frac{1}{\beta} \frac{1}{(\xi+1)} \frac{\partial \xi}{\partial T_{\mathrm{D}}}$.

Substitute Eqs. (38)-(42) into Eqs. (31)-(37), the model can be converted to

$\frac{\partial^{2} \xi}{\partial r_{\mathrm{D}}^{2}}+\frac{1}{r_{\mathrm{D}}} \frac{\partial \xi}{\partial r_{\mathrm{D}}}=\frac{1}{\left(C_{\mathrm{D}} e^{2 S}\right)} \frac{\partial \xi}{\partial T_{\mathrm{D}}}$,

$\left.\xi\right|_{T_{\mathrm{D}}=0}=0$

$\frac{\mathrm{d} p_{\mathrm{wD}}}{\mathrm{d} T_{\mathrm{D}}}-\left.\left(\frac{\partial p_{\mathrm{D}}}{\partial r_{\mathrm{D}}}\right)\right|_{r_{\mathrm{D}}=1}=1$,

where $p_{\mathrm{wD}}$ is dimensionless wellbore pressure.

External boundary conditions:

$\left.\lim p_{\mathrm{D}}\right|_{r_{\mathrm{e}} \rightarrow \infty}=0$ (infinite),

$\left.p_{\mathrm{D}}\right|_{r_{\mathrm{D}}=r_{\mathrm{eD}}}=0$ (constant pressure),

$\left.\frac{\partial p_{\mathrm{D}}}{\partial r_{\mathrm{D}}}\right|_{r_{\mathrm{D}}=r_{\mathrm{eD}}}=0$ (closed).

\section{(2) Linearization of dimensionless mathematical model}

Equation (32) is a nonlinear partial differential equation. The following variable modifications are introduced to solve the dimensionless mathematical model (Nie and Ding, 2010; Odeh and Babu, 1998):

$\left.\left(\frac{\partial \xi}{\partial r_{\mathrm{D}}}-\frac{\partial \xi}{\partial T_{\mathrm{D}}}-\beta \xi\right)\right|_{r_{\mathrm{D}}=1}=\beta$,

$\left.\lim \xi\right|_{r_{\mathrm{eD}} \rightarrow \infty}=0$ (infinite)

$\left.\xi\right|_{r_{\mathrm{D}}=r_{\mathrm{eD}}}=0$ (constant pressure),

$\left.\frac{\partial \xi}{\partial r_{\mathrm{D}}}\right|_{r_{\mathrm{D}}=r_{e D}}=0$ (closed).

$p_{\mathrm{D}}=-\frac{1}{\beta} \ln (\xi+1)$.

Then

$\frac{\partial p_{\mathrm{D}}}{\partial r_{\mathrm{D}}}=-\frac{1}{\beta} \frac{1}{(\xi+1)} \frac{\partial \xi}{\partial r_{\mathrm{D}}}$,

\section{(3) Solution to dimensionless mathematical model}

Introduce the Laplace transform based on $T_{\mathrm{D}}$ :

$L\left[\xi\left(r_{\mathrm{D}}, T_{\mathrm{D}}\right)\right]=\bar{\xi}\left(r_{\mathrm{D}}, u\right)=\int_{0}^{\infty} \xi\left(r_{\mathrm{D}}, T_{\mathrm{D}}\right) e^{-u T_{\mathrm{D}}} \mathrm{d} T_{\mathrm{D}}$.

The dimensionless mathematical model in Laplace space is as follows:

$\frac{\mathrm{d}^{2} \bar{\xi}}{\mathrm{d} r_{\mathrm{D}}^{2}}+\frac{1}{r_{\mathrm{D}}} \frac{\mathrm{d} \bar{\xi}}{\mathrm{d} r_{\mathrm{D}}}=\frac{u}{\left(C_{\mathrm{D}} e^{2 S}\right)} \bar{\xi}$,

$\left.\frac{\mathrm{d} \bar{\xi}}{\mathrm{d} r_{\mathrm{D}}}\right|_{r_{\mathrm{D}}=1}-(u+\beta) \bar{\xi}_{\mathrm{w}}=\frac{\beta}{u}$, 
$\left.\lim \bar{\xi}\right|_{r_{\mathrm{D}} \rightarrow \infty}=0$ (infinite)

$\left.\bar{\xi}\right|_{r_{\mathrm{D}}=r_{\mathrm{eD}}}=0$ (constant pressure)

$\left.\frac{\partial \bar{\xi}}{\partial r_{\mathrm{D}}}\right|_{r_{\mathrm{D}}=r_{\mathrm{eD}}}=0$ (closed $)$.

The general solution of the Eq. (50) is

$\bar{\xi}=A I_{0}\left(r_{\mathrm{D}} \sqrt{\varsigma}\right)+B K_{0}\left(r_{\mathrm{D}} \sqrt{\varsigma}\right)$

$\varsigma=u /\left(C_{\mathrm{D}} e^{2 S}\right)$

Substitute Eq. (55) into Eqs. (50) and (51):

$I_{0}(\sqrt{\varsigma}) \cdot A+K_{0}(\sqrt{\varsigma}) \cdot B-\bar{\xi}_{\mathrm{w}}=0$,

$\sqrt{\varsigma} I_{1}(\sqrt{\varsigma}) \cdot A-\sqrt{\varsigma} K_{1}(\sqrt{\varsigma}) \cdot B-(u+\beta) \bar{\xi}_{\mathrm{w}}=\beta / u$

Substitute Eq. (55) into Eqs. (52)-(54):

$\left.\lim \left[I_{0}\left(r_{\mathrm{eD}} \sqrt{\varsigma}\right) \cdot A+K_{0}\left(r_{\mathrm{eD}} \sqrt{\varsigma}\right) \cdot B\right]\right|_{r_{\mathrm{eD}} \rightarrow \infty}=0$

$I_{0}\left(r_{\mathrm{eD}} \sqrt{\varsigma}\right) \cdot A+K_{0}\left(r_{\mathrm{eD}} \sqrt{\varsigma}\right) \cdot B=0$

$I_{1}\left(r_{\mathrm{eD}} \sqrt{\varsigma}\right) \cdot A-K_{1}\left(r_{\mathrm{eD}} \sqrt{\varsigma}\right) \cdot B=0$

where $A$ and $B$ are undetermined coefficients; $I_{0}()$ is a modified Bessel function of the first kind, zero order; $I_{1}()$ is a modified Bessel function of the first kind, first order; $K_{0}($ ) is a modified Bessel function of the second kind, zero order; $K_{1}()$ is a modified Bessel function of the second kind, first order.

In Eqs. (57)-(61), there are three unknown numbers $(A$, $\left.B, \bar{\xi}_{\mathrm{w}}\right)$ and three equations, solutions to the model in Laplace space can be easily obtained by using linear algebra (Nie et al., 2011a, b), such as a Gauss-Jordan reduction.

In real space, $\xi_{\mathrm{w}}$ and the derivative $\left(\mathrm{d} \xi_{\mathrm{w}} / \mathrm{d} T_{\mathrm{D}}\right)$ can be obtained using a Stehfest numerical inversion (Stehfest, 1970) to convert $\xi_{\mathrm{w}}$ back to $\xi_{\mathrm{w}}$, and then dimensionless wellbore pressure $\left(p_{\mathrm{wD}}\right)$ and the derivative $\left(\mathrm{d} p_{\mathrm{wD}} / \mathrm{d} T_{\mathrm{D}}\right)$ can be obtained by substituting $\xi_{\mathrm{w}}$ into Eq. (38). The standard log-log type curves of well-test analysis (Nie et al., 2012b, c) of $p_{\mathrm{wD}}$ and $\left(p_{\mathrm{wD}}^{\prime} \cdot t_{\mathrm{D}} / C_{\mathrm{D}}\right)$ vs. $t_{\mathrm{D}} / C_{\mathrm{D}}$ can then be obtained.

\subsubsection{Gas flow in a finite formation}

\section{(1) Establishment of mathematical model}

Governing differential equation in a radial cylindrical system

$\frac{\partial^{2} \psi}{\partial r^{2}}+\frac{1}{r} \frac{\partial \psi}{\partial r}=\frac{\varphi \mu C_{\mathrm{t}}}{3.6 k} \frac{\partial \psi}{\partial t}$,

where $C_{\mathrm{t}}$ is total compressibility of rock and gas, $\mathrm{MPa}^{-1}$; $k$ is radial formation permeability, $\mu \mathrm{m}^{2} ; \psi$ is gas pseudopressure, $\mathrm{MPa}^{2}(\mathrm{mPas})^{-1} ; r$ is radial radius from the centre of wellbore, $\mathrm{m}$; $t$ is well production time, $\mathrm{h}$.

Initial condition

$\left.\psi\right|_{t=0}=\psi_{\mathrm{i}}=2 \int_{p_{\mathrm{sc}}}^{p_{\mathrm{i}}} \frac{p_{\mathrm{i}}}{\mu_{\mathrm{i}} Z_{\mathrm{i}}} \mathrm{d} p_{\mathrm{i}}$,

where the subscript "i" means "initial".

Well production condition based on effective radius

$$
\begin{aligned}
& \left.\frac{k h}{\mu}\left(\frac{Z}{2 p} r \frac{\partial \psi}{\partial r}\right)\right|_{r=r_{\mathrm{wa}}}-0.04421 C_{\mathrm{s}} \frac{\mu Z}{2 p} \frac{\mathrm{d} \psi_{\mathrm{w}}}{\partial t} \\
& =1.842 \times 10^{-3} q_{\mathrm{g}},
\end{aligned}
$$

where $C_{\mathrm{s}}$ is a wellbore storage coefficient, $\mathrm{m}^{3} \mathrm{MPa}^{-1} ; \psi_{\mathrm{w}}$ is wellbore pseudo-pressure, $\mathrm{MPa}^{2}(\mathrm{mPas})^{-1} ; q_{\mathrm{g}}$ is well rate at bottom hole, $\mathrm{m}^{3} \mathrm{~d}^{-1} ; r_{\text {wa }}$ is effective wellbore radius, $\mathrm{m}$.

At the external boundary for a finite formation:

$\left.\psi\right|_{r=r_{\mathrm{e}}}=\psi_{\mathrm{i}}($ constant pressure $)$,

$\left.\frac{\partial \psi}{\partial r}\right|_{r=r_{\mathrm{e}}}=0$ (closed)

where $r_{\mathrm{e}}$ is the external boundary radius, $\mathrm{m}$.

\section{(2) Solution of the nonlinear mathematical model}

Because well production pressure is largely depleted near the wellbore, we use logarithmic-uniform radial meshes in space to discretize the equation and obtain relatively dense grids near the wellbore. A new space variable is taken by

$R=\ln (r)$.

The mathematical model can be converted to

$\frac{\partial^{2} \psi}{\partial R^{2}}+\frac{\partial \psi}{\partial R}=e^{2 R} \frac{\varphi \mu C_{\mathrm{t}}}{3.6 k} \frac{\partial \psi}{\partial t}$,

$\left.k h\left(\frac{Z}{2 p} \frac{1}{e^{R}} \frac{\partial \psi}{\partial R}\right)\right|_{R=\ln \left(r_{\mathrm{wa}}\right)}-0.04421 C_{\mathrm{s}} \frac{\mu Z}{2 p} \frac{\mathrm{d} \psi_{\mathrm{w}}}{\partial t}$

$=1.842 \times 10^{-3} q_{\mathrm{g}}$, 
$\left.\psi\right|_{R=\ln \left(r_{\mathrm{e}}\right)}=\psi_{\mathrm{i}}$ (constant pressure)

$$
\begin{aligned}
& \left.\frac{\partial \psi}{\partial R}\right|_{R=\ln \left(r_{\mathrm{e}}\right)}=0(\text { closed }), \\
& \left.\psi\right|_{t=0}=\psi_{\mathrm{i}},\left.p\right|_{t=0}=p_{\mathrm{i}},\left.\mu\right|_{t=0}=\mu_{\mathrm{i}},\left.C_{\mathrm{t}}\right|_{t=0} \\
& \quad=C_{\mathrm{ti}},\left.Z\right|_{t=0}=Z_{\mathrm{i}} .
\end{aligned}
$$

The central difference method is employed to solve the model:

$$
\begin{aligned}
& \frac{\psi_{j-1}^{n+1}-2 \psi_{j}^{n+1}+\psi_{j+1}^{n+1}}{(\Delta R)^{2}}+\frac{\psi_{j+1}^{n+1}-\psi_{j-1}^{n+1}}{2 \Delta R} \\
& =e^{2(j \Delta R)} \frac{\varphi\left(\mu C_{\mathrm{t}}\right)_{j}^{n}}{3.6 k} \frac{\psi_{j}^{n+1}-\psi_{j}^{n}}{\Delta t}, \\
& k h\left(\frac{Z}{2 p}\right)_{\mathrm{w}}^{n} \frac{1}{e^{\ln \left(r_{\mathrm{wa}}\right)}} \frac{\psi_{1}^{n+1}-\left(\psi_{\mathrm{w}}\right)^{n+1}}{\Delta R}-0.04421 C_{\mathrm{s}}\left(\frac{\mu Z}{2 p}\right)_{\mathrm{w}}^{n} \\
& \frac{\left(\psi_{\mathrm{w}}\right)^{n+1}-\left(\psi_{\mathrm{w}}\right)^{n}}{\Delta t}=1.842 \times 10^{-3} q_{\mathrm{g}},
\end{aligned}
$$$$
\psi_{J}^{n+1}=\psi_{\mathrm{i}}(\text { constant pressure }),
$$

$$
\frac{\psi_{J}^{n+1}-\psi_{J-1}^{n+1}}{\Delta R}=0 \text { (closed) }
$$

$\psi_{j}^{0}=\psi_{\mathrm{i}}, p_{j}^{0}=p_{\mathrm{i}}, \mu_{j}^{0}=\mu_{\mathrm{i}},\left(C_{\mathrm{t}}\right)_{j}^{0}=C_{\mathrm{ti}}, Z_{j}^{0}=Z_{\mathrm{i}}$,

where $n$ is the previous time level; $(n+1)$ is the current time level; 0 is the initial time; $j$ is the grid node; $J$ is the number of grid node at external boundary; $\Delta t$ is the time step size; $\Delta R$ is the grid step size.

Note that Eqs. (68) and (69) are nonlinear equations because $\mu, Z, C_{\mathrm{t}}$ are stealth functions of pressure and pseudopressure, therefore, in order to solve the model, we used the previous time level $\left(\mu C_{\mathrm{t}}\right)_{j}^{n}$ in Eq. (73), and $\left(\frac{Z}{2 p}\right)_{\mathrm{w}}^{n}$ and $\left(\frac{\mu Z}{2 p}\right)_{\mathrm{w}}^{n}$ in Eq. (74) to approximate the current time level.

\section{Analysis of nonlinear flow characteristics}

\subsection{Simulating pressure transients of liquid flow}

\subsubsection{Type curves of pressure transients}

Type curves reflect properties of underground formations. Type curves graphically show the process and characteristics of fluid flow in reservoirs.

\section{(1) Type curves of the linear flow model}

The standard log-log type curves of the linear flow model (see Fig. 1) are well known. An entire flow process can be discerned from the type curves:

i. Regime I, pure wellbore storage regime, slope of pressure and the pressure derivative both equal one.

ii. Regime II, wellbore storage and skin effect regime, shape of the derivative curve is a "hump".

iii. Regime III, radial flow regime, slope of the pressure derivative curve equals zero, and all the pressure derivative curves converge to the " 0.5 line", indicating the logarithmic value of the pressure derivative is 0.5 .

iv. Regime IV, external boundary response regime. For a constant pressure boundary, where the pressure derivative curve decreases, transient flow ultimately becomes steady state. For closed boundary, as the pressure derivative curve increases, transient flow ultimately becomes pseudo-steady state, where the type curves converge to a straight line with unit slope.

Figure 1 shows type curve characteristics as controlled by different values of parameter group $C_{\mathrm{D}} e^{2 S}$. A larger $C_{\mathrm{D}} e^{2 S}$ leads to a higher location of the dimensionless pressure curve.

\section{(2) Type curves of nonlinear flow model}

Figures 2-5 show the typical nonlinear flow characteristics and flow processes of vertical well production in a homogenous formation. Figure 2 contains the type curves of a nonlinear flow model with an infinite boundary. The type curves are obviously controlled by the dimensionless coefficient of nonlinear term $\beta$. Pressure transients were simulated by setting $\beta=0,0.01,0.05$ and 0.1 . A larger $\beta$ leads to smaller dimensionless pressure curves and associated derivative curves. The " $\beta=0$ " curves are associated with the linear flow model. Three main flow regimes can be easily discerned from the type curves:

i. Regime I, pure wellbore storage regime, there are no differences in type curves between the two flow models because liquid in formation does not start to flow and the influence of the nonlinear quadratic pressure gradient term is only produced for flow in formation. Wellbore pressure transients are not affected by the nonlinearity of oil flow in this regime.

ii. Regime II, wellbore storage and skin effect regime, there are obvious differences in type curves between the two flow models. The nonlinearity of liquid flow positively influences the pressure transients. A larger $\beta$ means a stronger nonlinear effect of liquid flow on the type curves. 


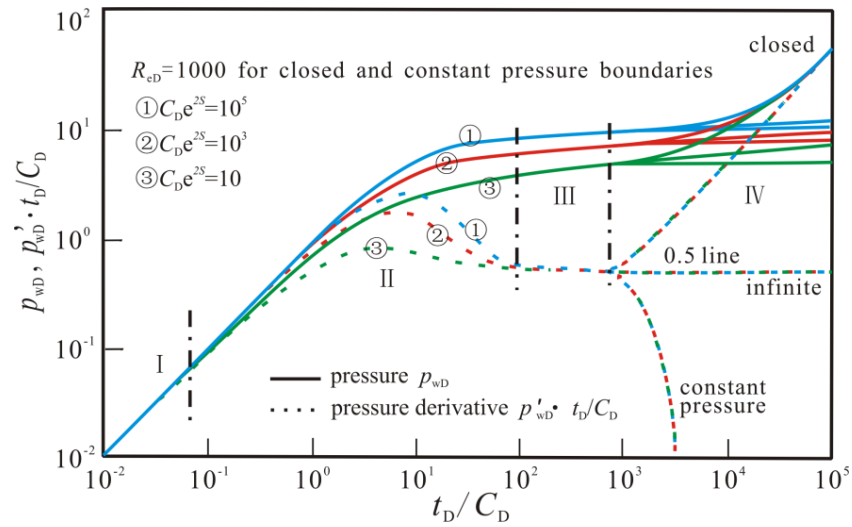

Fig. 1. Type curves for linear flow models used for comparison with those from nonlinear flow models. Type curve characteristics controlled by parameter group $C_{\mathrm{D}} e^{2 S}$ and external boundary conditions are shown. Four main flow regimes were recognised: pure wellbore storage regime (I), wellbore storage and skin effect regime (II), radial flow regime (III), and external boundary response regime (IV). Derivative curves converged to the " 0.5 " line in the radial flow regime for infinite formation, decreased for constant pressure boundary and increased for closed boundary. Pressure curves and their derivative curves ultimately converged to a straight line with a slope of one.

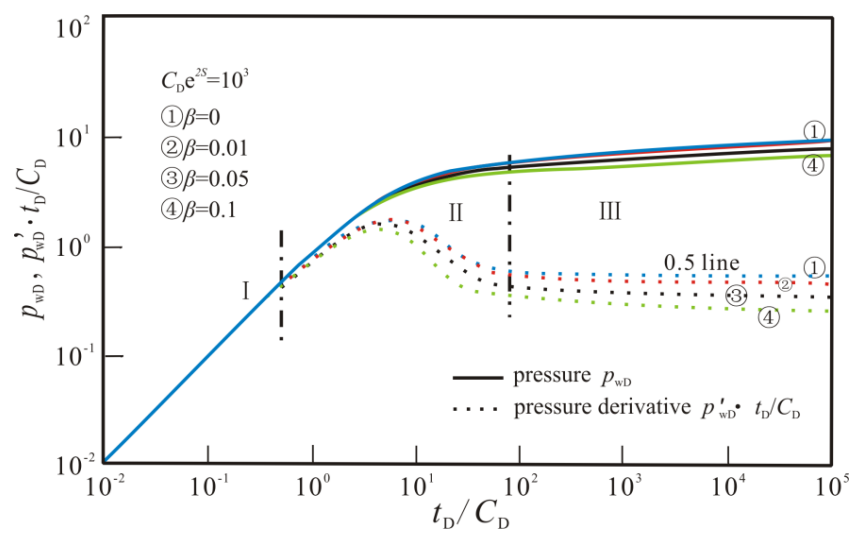

Fig. 2. Type curves for the nonlinear well-test model with an infinite boundary used in the analysis of nonlinear flow processes. The type curve characteristics are controlled by different values of the dimensionless coefficient of the nonlinear term $\beta$. Pressure transients were simulated by setting $\beta=0,0.01,0.05$, and 0.1 . Pressure curves and their derivative curves were positively affected by $\beta$. Derivative curves did not converge to the " 0.5 " line in the radial flow regime. The " $\beta=0$ " curves were linear flow model curves.

iii. Regime III, radial flow regime, different type curves are associated with the two flow models. Pressure derivative curves of the nonlinear flow model do not conform to the " 0.5 line" law. The curves are located along the " 0.5 line" and are inclined instead of horizontal (see Figs. 25). As time elapses, the pressure derivative curves gradually deviate from the " 0.5 line".

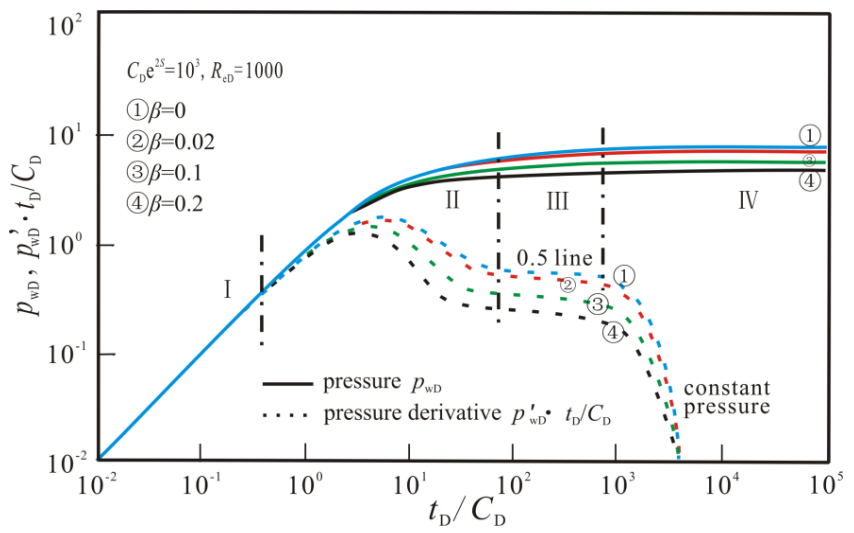

Fig. 3. Type curves for the nonlinear well-test model with a constant pressure boundary used for analysis of nonlinear flow processes. The type curve characteristics are controlled by different values of $\beta$. Pressure transients were simulated by setting $\beta=0,0.02,0.1$ and 0.2 . Derivative curves decreased and ultimately converged to a point.

Figure 3 contains the nonlinear flow model type curves with constant pressure boundaries. Pressure transients were simulated by setting $\beta=0,0.02,0.1$, and 0.2 . Nonlinear flow characteristics in regimes I-III are similar to the nonlinear flow model type curves with an infinite boundary. The type curves in regime IV show that the pressure derivative curves decrease and ultimately converge at a point.

Figure 4 contains the nonlinear flow model type curves with closed boundaries. Pressure transients were simulated by setting $\beta=0,0.02,0.1$, and 0.2 . Nonlinear flow characteristics in Regimes I-III are similar to infinite boundary type curves. The type curves in Regime IV show that the pressure curves and their derivative curves increase and ultimately converge to a straight line whose slope is smaller than one, instead of one, which is different from the linear flow model.

Figure 5 shows the type curve characteristics that are controlled by values associated with the parameter group $C_{\mathrm{D}} e^{2 S}$. Pressure transients were simulated by setting $C_{\mathrm{D}} e^{2 S}=10^{5}$, $10^{3}$ and 10. A larger $C_{\mathrm{D}} e^{2 S}$ leads to larger dimensionless pressure curves, which is similar to the linear flow model. Dimensionless pressure curve characteristics are completely different from those of the linear flow model. Derivative curves cross at a point (see point A on the caption of Fig. 5) before the radial flow regime. A larger $C_{\mathrm{D}} e^{2 S}$ leads to larger derivative curves in Regime II and smaller derivative curves in Regime III.

\subsubsection{Quantitative analysis of nonlinear influence}

Pressure curves and the derivative curves of nonlinear flow models deviate gradually from those of linear flow models with time. "DV" and "RDV" show the quantitative 


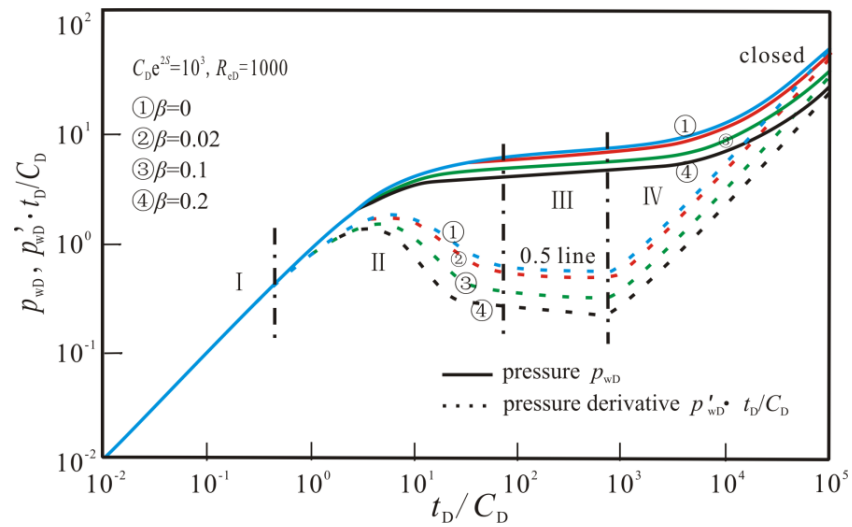

Fig. 4. Type curves of nonlinear well-test model with a closed boundary used for the analysis of nonlinear flow processes. The figure shows the type curve characteristics controlled by different values of $\beta$. Pressure transients were simulated by setting $\beta=0,0.02$, 0.1 and 0.2 . Pressure curves and the associated derivative curves increase and ultimately converged to a straight line whose slope is smaller than one.

differences between type curves. They are defined as

$\mathrm{DV}=\mid$ value of linear model - value of nonlinear model $\mid$

$\mathrm{RDV}=\frac{\mathrm{DV}}{\text { value of linear model }} \cdot 100 \%$,

where DV is the differential value between linear and nonlinear models and RDV is the relative differential value between linear and nonlinear models.

Tables 1 and 2 show the quantitative differences of nonlinear influence on type curves for " $\beta=0.01$ " and " $\beta=$ 0.1 ", respectively. Dimensionless pressure values and their derivative values in Tables 1 and 2 were calculated by setting $C_{\mathrm{D}} e^{2 S}$ as $10^{3}$, the corresponding type curves are shown in Fig. 3. The tables show that dimensionless pressure and its derivative differ between linear and nonlinear models. For " $\beta=0.01 "$ and " $t_{\mathrm{D}} / C_{\mathrm{D}}=10^{2} ", \mathrm{DV}$ and RDV of pressure are 0.1711 and $2.81 \%$, respectively; when " $t_{\mathrm{D}} / C_{\mathrm{D}}=10^{5} ", \mathrm{DV}$ and RDV of pressure are 0.4311 and $4.48 \%$, respectively; when " $t_{\mathrm{D}} / C_{\mathrm{D}}=10^{2}$ ", $\mathrm{DV}$ and $\mathrm{RDV}$ of pressure derivative are 0.0348 and $6.17 \%$, respectively; when " $t_{\mathrm{D}} / C_{\mathrm{D}}=10^{5}$ ", DV and RDV of pressure derivative are 0.0439 and $8.78 \%$, respectively. For " $\beta=0.1$ " and $" t_{\mathrm{D}} / C_{\mathrm{D}}=10^{2} ", \mathrm{DV}$ and RDV of pressure are 1.3030 and $21.38 \%$, respectively; when " $t_{\mathrm{D}} / C_{\mathrm{D}}=10^{5}$ ", $\mathrm{DV}$ and $\mathrm{RDV}$ of pressure are 2.8667 and $29.82 \%$, respectively; when " $t_{\mathrm{D}} / C_{\mathrm{D}}=10^{2}$ ", $\mathrm{DV}$ and RDV of pressure derivative are 0.2212 and $39.24 \%$, respectively; when " $t_{\mathrm{D}} / C_{\mathrm{D}}=10^{5}$ ", DV and RDV of pressure derivative are 0.2457 and $49.14 \%$, respectively.

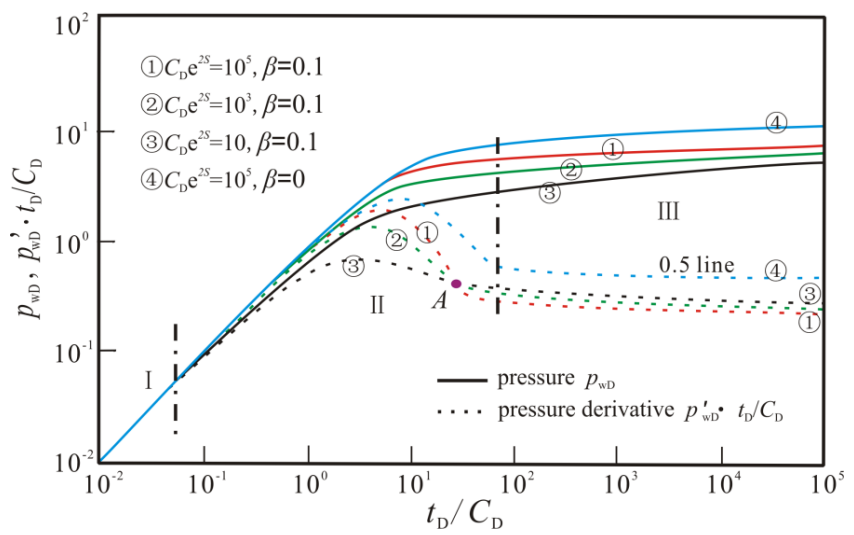

Fig. 5. Type curves of the nonlinear well-test model with an infinite boundary used for analysis of nonlinear flow processes. The type curve characteristics are controlled by different values of the parameter group $C_{\mathrm{D}} e^{2 S}$. Pressure transients were simulated by setting $C_{\mathrm{D}} e^{2 S}=10^{5}, 10^{3}$, and 10 . Derivative curves crossed at a point (see point $\mathrm{A}$ on the caption) before the radial flow regime.

DV and RDV increase over time (Tables 1 and 2). RDV of the pressure derivative is greater than that of pressure at a

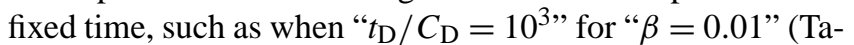
ble 1). The RDV of the pressure derivative is $6.91 \%$, which is greater than that of pressure, $3.43 \%$. It can be observed from the tables that DV and RDV increase in parallel with $\beta$, such as when " $t_{\mathrm{D}} / C_{\mathrm{D}}=10^{4}$ ", $\mathrm{RDV}$ of pressure for " $\beta=0.01$ " is $3.96 \%$ and RDV of pressure for " $\beta=0.1$ " is $27.39 \%$.

According to the equation, $\beta=(1.842 \times$ $\left.10^{-3} q B \mu C_{\rho}\right) /(k h)$, and probable values of $\beta$ (Table 3 ), it is demonstrated that $\beta$ is proportional to liquid viscosity, $\mu$, and inversely proportional to formation permeability, $k$, and formation thickness, $h$. Formations with low permeability, heavy oil or thin thickness have a larger $\beta$, causing the influence of nonlinearity to be more intense for these formations.

In general, flow of fluid in porous media is a nonlinear process and the nonlinear quadratic pressure gradient term should be retained in diffusion equations.

\subsubsection{Comparision to Chakrabarty's model}

Homogenous reservoir models are among recent pressuretransient models containing the quadratic pressure gradient term. However, these models do not study pressure-transient curves of well-test analysis, such as Marshall (2009), Giachetti and Maroscia (2008), Liang et al. (2001); while others do not model homogenous reservoirs, such as Tong and Wang (2005), Bai et al. (1994). The solutions of these models cannot be compared to the model discussed here. Chakrabarty et al. (1993b) studied a nonlinear pressuretransient model which does not consider skin factor and plotted a group of $\log -\log$ pressure-transient curves based on $t_{\mathrm{D}}$. 
Table 1. Theoretical offset of type curves caused by the nonlinear term $(\beta=0.01)$.

\begin{tabular}{|c|c|c|c|c|c|c|c|c|}
\hline \multirow[t]{2}{*}{$t_{\mathrm{D}} / C_{\mathrm{D}}$} & \multicolumn{2}{|c|}{$p_{\mathrm{wD}}$} & \multirow[t]{2}{*}{ DV } & \multirow[t]{2}{*}{ RDV (\%) } & \multicolumn{2}{|c|}{$p_{\mathrm{wD}}^{\prime} \cdot t_{\mathrm{D}} / C_{\mathrm{D}}$} & \multirow[t]{2}{*}{ DV } & \multirow[t]{2}{*}{ RDV (\%) } \\
\hline & linear & nonlinear & & & linear & nonlinear & & \\
\hline $10^{2}$ & 6.0943 & 5.9232 & 0.1711 & 2.81 & 0.5638 & 0.5290 & 0.0348 & 6.17 \\
\hline $10^{3}$ & 7.3048 & 7.0544 & 0.2504 & 3.43 & 0.5078 & 0.4727 & 0.0351 & 6.91 \\
\hline $10^{4}$ & 8.4627 & 8.1271 & 0.3355 & 3.96 & 0.5005 & 0.4614 & 0.0392 & 7.83 \\
\hline $10^{5}$ & 9.6147 & 9.1836 & 0.4311 & 4.48 & 0.5001 & 0.4562 & 0.0439 & 8.78 \\
\hline
\end{tabular}

Explanations: $\beta$ is the dimensionless coefficient of the nonlinear term; $t_{\mathrm{D}}$ is dimensionless time; $C_{\mathrm{D}}$ is dimensionless wellbore storage coefficient; $p_{\mathrm{wD}}$ is dimensionless pressure; $p_{\mathrm{wD}}^{\prime}$ is dimensionless pressure derivative; DV is differential value; RDV is relative differential value. The quantitative analysis of nonlinear influence was calculated by setting $C_{\mathrm{D}} e^{2 \mathrm{~S}}=10^{3}$ and $\beta=0.01$. Corresponding type curves are shown in Fig. 2 .

Table 2. Theoretical offset of type curves caused by the nonlinear term $(\beta=0.1)$.

\begin{tabular}{|c|c|c|c|c|c|c|c|c|}
\hline \multirow[t]{2}{*}{$t_{\mathrm{D}} / C_{\mathrm{D}}$} & \multicolumn{2}{|c|}{$p_{\mathrm{wD}}$} & \multirow[t]{2}{*}{ DV } & \multirow[t]{2}{*}{$\operatorname{RDV}(\%)$} & \multicolumn{2}{|c|}{$p_{\mathrm{wD}}^{\prime} \cdot t_{\mathrm{D}} / C_{\mathrm{D}}$} & \multirow[t]{2}{*}{ DV } & \multirow[t]{2}{*}{$\operatorname{RDV}(\%)$} \\
\hline & linear & nonlinear & & & linear & nonlinear & & \\
\hline $10^{2}$ & 6.0943 & 4.7913 & 1.3030 & 21.38 & 0.5638 & 0.3425 & 0.2212 & 39.24 \\
\hline $10^{3}$ & 7.3048 & 5.5001 & 1.8047 & 24.71 & 0.5078 & 0.2902 & 0.2176 & 42.85 \\
\hline $10^{4}$ & 8.4627 & 6.1444 & 2.3183 & 27.39 & 0.5005 & 0.2701 & 0.2304 & 46.04 \\
\hline $10^{5}$ & 9.6147 & 6.7480 & 2.8667 & 29.82 & 0.5001 & 0.2543 & 0.2457 & 49.14 \\
\hline
\end{tabular}

Explanations: $\beta$ is the dimensionless coefficient of the nonlinear term; $t_{\mathrm{D}}$ is dimensionless time; $C_{\mathrm{D}}$ is dimensionless wellbore storage coefficient; $p_{\mathrm{wD}}$ is dimensionless pressure; $p_{\mathrm{wD}}^{\prime}$ is dimensionless pressure derivative; DV is differential value; RDV is relative differential value. The quantitative analysis of nonlinear influence was calculated by setting $C_{\mathrm{D}} e^{2 \mathrm{~S}}=10^{3}$ and $\beta=0.1$. Type curves are shown in Fig. 2 .

Table 3. Probable values for the dimensionless coefficient of the nonlinear term.

\begin{tabular}{cccccc}
\hline $\begin{array}{c}k \\
\left(\times 10^{-3} \mu \mathrm{m}^{2}\right)\end{array}$ & $\begin{array}{c}\mu \\
(\mathrm{mPas})\end{array}$ & $\beta$ & $\begin{array}{c}k \\
\left(\times 10^{-3} \mu \mathrm{m}^{2}\right)\end{array}$ & $\begin{array}{c}\mu \\
(\mathrm{mPas})\end{array}$ & $\beta$ \\
\hline 100 & 25 & 0.00115 & 100 & 100 & 0.00460 \\
10 & 25 & 0.01150 & 10 & 100 & 0.04600 \\
1 & 25 & 0.11500 & 1 & 100 & 0.46000 \\
\hline
\end{tabular}

Explanations: $k$ is formation permeability; $\mu$ is liquid viscosity; $\beta$ is dimensionless coefficient of the nonlinear term; $\beta$ was calculated according to its definition under a set of fixed parameters: set liquid rate $q=25 \mathrm{~m}^{3} \mathrm{~d}^{-1}$; liquid volume factor $B=1.004$; formation thickness $h=10 \mathrm{~m}$ and liquid compressibility $C_{\rho}=0.001 \mathrm{MPa}^{-1}$.

The model of this article considered skin factor and regulated skin factor $(S)$ and wellbore storage coefficient $\left(C_{\mathrm{D}}\right)$ to a parameter group $\left(C_{\mathrm{D}} e^{2 S}\right) . S$ would need to be set as zero to make an effective comparison with Chakrabarty's model. In addition, the log-log pressure-transient curves were plotted based on $\left(t_{\mathrm{D}} / C_{\mathrm{D}}\right)$, therefore the abscissa would need to be converted to $t_{\mathrm{D}}$. Please note that the type curves based on $\left(t_{\mathrm{D}} / C_{\mathrm{D}}\right)$ will cross over the origin of coordinates $\left(10^{-2}\right.$, $10^{-2}$ ) and the type curves based on $t_{\mathrm{D}}$ do not. Figures 8 and 9 of Chakrabarty et al. (1993b) are log-log pressure curves and $\log -\log$ pressure derivative curves, respectively. In order to have a convenient comparison, the same parameter values and the same range of coordinate scales as those shown Figs. 8 and 9 were used. Equation (6a) of Chakrabarty et al. (1993b) defined the dimensionless quadratic gradient coeffi- cient as

$\alpha=-\frac{q \mu c}{2 \pi k h}$,

where $\alpha$ is the dimensionless quadratic gradient coefficient; $q$ is rate at wellbore, $\mathrm{cm}^{3} \mathrm{~s}^{-1} ; \mu$ is viscosity, $\mathrm{mPas} ; c$ is fluid compressibility, $\mathrm{atm}^{-1} ; k$ is permeability, $\mathrm{D} ; h$ is formation thickness, $\mathrm{cm}$.

Comparing the definition of $\alpha$ in Chakrabarty et al. (1993b) with the definition of $\beta$ in this article, they used the rate at wellbore and we used the rate at wellhead, and $\beta$ is the opposite number of $\alpha$. Figures 6 and 7 show the comparisons of pressure curve and pressure derivative curve, respectively. The solutions of our model are completely the same as those of the model in Chakrabarty et al. (1993b). In conclusion, our model can be reduced to the model of 


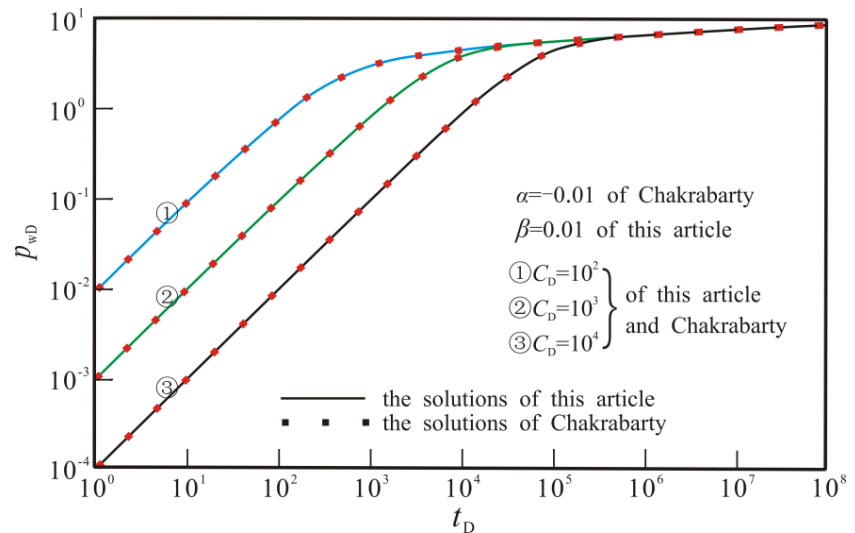

Fig. 6. Pressure curve comparisons with Chakrabarty et al. (1993b) for homogenous infinite formation. Full lines are pressure curves from this article and dotted lines are pressure curves associated with Chakrabarty et al. (1993b). $\beta$ is the opposite number of $\alpha$. For convenience, the same parameter values are set. The solutions of this article are the same as those of Chakrabarty et al. (1993b).

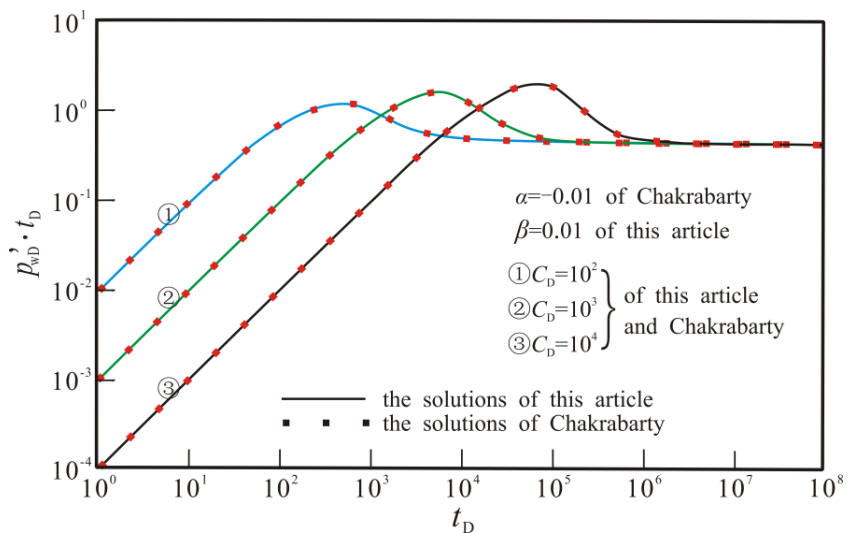

Fig. 7. Pressure derivative curve comparisons with Chakrabarty et al. (1993b) for homogenous infinite formation. The solutions of this article are the same as those of Chakrabarty et al. (1993b).

\subsection{Simulating gas flow pressure transients}

\subsubsection{Data preparation}

PVT parameters of gas can be calculated from gas composition (Hagoort, 1988). Using an example gas well of sandstone formation, basic data of formation and gas composition are shown in Table 4 (formation at mid-depth is $1380 \mathrm{~m}$; formation thickness is $9.4 \mathrm{~m}$; formation porosity is 0.08 ; formation permeability is $0.014 \mu \mathrm{m}^{2}$; compressibility of formation rock is $0.00038 \mathrm{MPa}^{-1}$; the well radius is $0.062 \mathrm{~m}$; formation temperature is $338.5 \mathrm{~K}$; formation pressure is $20.5 \mathrm{MPa}$; and mole composition of methane, ethane, propane and nitrogen are $99.711 \%, 0.092 \%, 0.03 \%$ and $0.167 \%$, respectively). Formation parameter data are from well logging interpretations and mole composition data are from laboratory tests. Gas property parameters are a function of pressure and temperature and were calculated using mole composition data (such as gas compressibility, viscosity, compressibility factor and pseudo-pressure) in the commercial software, Saphir. Figure 8 shows the relationship curves between gas property parameters and pressure. The gas compressibility factor decreases and then increases with an increase in pressure (Fig. 8a). Both gas viscosity and pseudopressure increase with an increase in pressure (Fig. $8 \mathrm{~b}$ and c). Gas compressibility decreases with an increase in pressure (Fig. 8d). Compressibility is large at low pressures, especially in critical isotherm conditions (Marshall, 2009). Critical pressures calculated using Saphir are $4.62 \mathrm{MPa}$ with gas compressibility of the example well $=0.024 \mathrm{MPa}^{-1}$. Gas flow in formation is a nonlinear process as shown by changes in property parameters with pressure. For convenience, the following formulations were regressed using polynomial or 
Table 4. Basic data from the simulated well.

\begin{tabular}{|c|c|c|c|c|c|c|c|c|c|c|c|c|}
\hline \multirow[t]{2}{*}{$\begin{array}{l}H_{\mathrm{m}} \\
(\mathrm{m})\end{array}$} & \multirow[t]{2}{*}{$\begin{array}{c}h \\
(\mathrm{~m})\end{array}$} & \multirow[t]{2}{*}{$\varphi$} & \multirow[t]{2}{*}{$\begin{array}{c}k \\
\left(\mu \mathrm{m}^{2}\right)\end{array}$} & \multirow[t]{2}{*}{$\begin{array}{c}C_{\mathrm{f}} \\
\left(\mathrm{MPa}^{-1}\right)\end{array}$} & \multirow[t]{2}{*}{$\begin{array}{l}r_{\mathrm{m}} \\
(\mathrm{m})\end{array}$} & \multirow[t]{2}{*}{$\begin{array}{c}T \\
(\mathrm{~K})\end{array}$} & \multirow[t]{2}{*}{$\begin{array}{c}p \\
(\mathrm{MPa})\end{array}$} & \multicolumn{5}{|c|}{$\begin{array}{l}\text { mole composition } \\
\qquad(\%)\end{array}$} \\
\hline & & & & & & & & $\mathrm{N}_{2}$ & $\mathrm{CO}_{2}$ & $\mathrm{C}_{1}$ & $\mathrm{C}_{2}$ & $\mathrm{C}_{3}$ \\
\hline 1380 & 9.4 & 0.08 & 0.014 & 0.00038 & 0.062 & 338.5 & 20.5 & 0.167 & - & 99.711 & 0.092 & 0.030 \\
\hline
\end{tabular}

Explanations: $H_{\mathrm{m}}$ is formation mid-depth; $h$ is formation thickness; $\varphi$ is formation porosity; $k$ is formation permeability; $C_{\mathrm{f}}$ is compressibility of formation rock; $r_{\mathrm{W}}$ is well radius; $T$ is formation temperature; $p$ is formation pressure; $\mathrm{N}_{2}$ is nitrogen; $\mathrm{CO}_{2}$ is carbon dioxide; $\mathrm{C}_{1}$ is methane; $\mathrm{C}_{2}$ is ethane; $\mathrm{C}_{3}$ is propane.

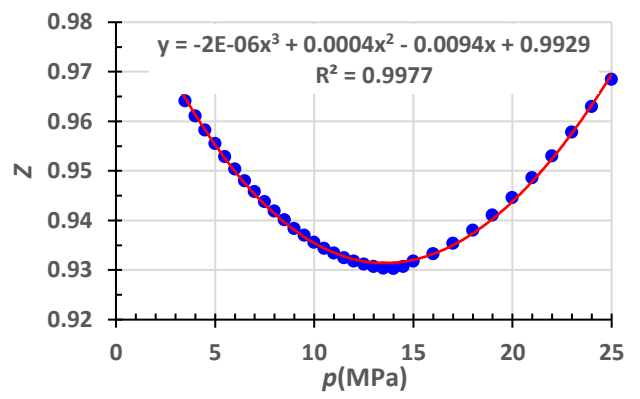

(a) Relationship curve of $Z$ with $p$

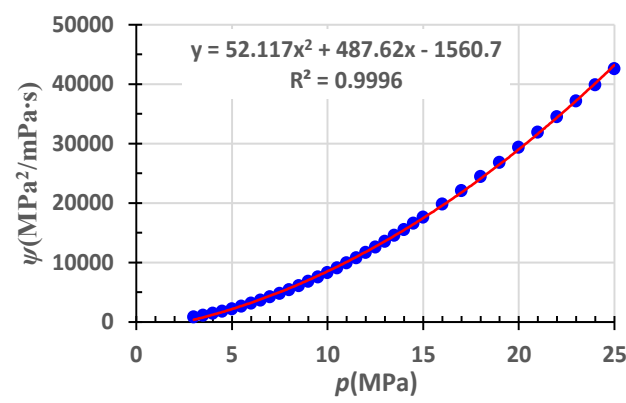

(c) Relationship curve of $\psi$ with $p$

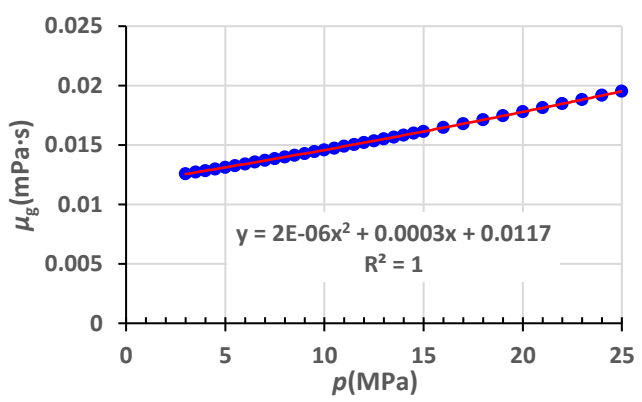

(b) Relationship curve of $\mu_{\mathrm{g}}$ with $p$

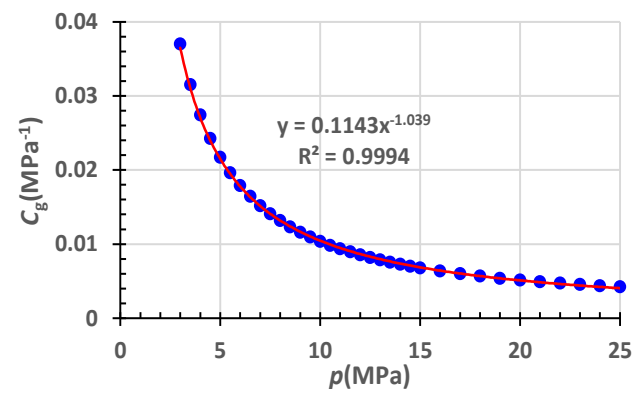

(d) Relationship curve of $C_{\mathrm{g}}$ with $p$

Fig. 8. Relationship curves of gas viscosity $(\mu)$, gas compressibility $\left(C_{\mathrm{g}}\right)$, compressibility factor $(Z)$ and pseudo-pressure $(\psi)$ with pressure $(p)$ for the example well. Parameters in the $(3 \sim 25)$ MPa pressure range were calculated using gas compositions found in the commercial software, Saphir. In order to conveniently calculate these parameters in numerical simulations, relationship equations were regressed with pressure using polynomial or power functions in Microsoft Excel.

power functions in Microsoft Excel:

$\mu=2 \times 10^{-6} p^{2}+0.0003 p+0.0117$,

$C_{\mathrm{g}}=0.1143 p^{-1.039}$

$Z=-2 \times 10^{-6} p^{3}+4 \times 10^{-4} p^{2}-0.0094 p+0.9929$,

$\psi=52.117 p^{2}+487.62 p-1560.7$.

In numerical simulations, each value of a property parameter in the current time level was approximated using a value associated with a previous time level. Each value of a property parameter in the previous time level can be calculated using Eqs. (81)-(83). Pressure transients can be simulated simulta- neously according to the relationship formulation of pseudopressure with pressure (Eq. 84).

In order to compare gas and oil flow, numerical simulations must be done under the same formation and well production conditions. Wellhead gas rate of the example well is $4.3 \times 10^{4} \mathrm{~m}^{3} \mathrm{~d}^{-1}$, and the bottom hole gas rate is equal to the product of the gas volume factor $B_{\mathrm{g}}(0.006)$ with a wellhead rate of $259 \mathrm{~m}^{3} \mathrm{~d}^{-1}$. If one was to simulate oil flow in such a sandstone formation with $9.4 \mathrm{~m}$ thickness and 0.08 porosity, the oil rate at the bottom hole would not reach $259 \mathrm{~m}^{3} \mathrm{~d}^{-1}$. Therefore, we simulated pressure transients by setting a relatively small bottom hole rate $\left(20 \mathrm{~m}^{3} \mathrm{~d}^{-1}\right)$ for both gas and oil production. With similar formation and well production conditions, property parameters of oil must be prepared before 
numerical simulations. We set oil viscosity and compressibility as $2 \mathrm{mPas}$ and $0.0034 \mathrm{MPa}^{-1}$, respectively and ignored changes in oil viscosity and compressibility with depletion of pressure. In addition, the wellbore storage coefficient and skin factor were set as $0.001 \mathrm{~m}^{3} \mathrm{MPa}^{-1}$ and 0.5 , respectively, with a $3000 \mathrm{~m}$ closed external boundary for the formation. Substituting the above data into Eqs. (57)-(61) for oil wells and Eqs. (73)-(77) for gas wells, wellbore pressure transients were calculated under the above conditions.

\subsubsection{Numerical simulation results}

Figure 9 shows the numerical simulation results for both gas and oil well production. The horizontal coordinate represents production time $(t)$ and the vertical coordinate represents production pressure drop $(\Delta p)$, or production pseudopressure drop $(\Delta \psi)$. Simulated production time is $60 \mathrm{~h}$. Figure 9 shows (1) the location of pseudo-pressure and its derivative curves (curve (1) are at their highest because the value of pseudo-pressure is larger than that of pressure (see Table 5); and (2) the location of pressure and its derivative curves for oil well production (curve (2)) is higher than that of gas well production because oil wells need a larger pressure drop for the same rate of production. The model assumes well production is at a constant volume rate. The very high dilatability of gas with the depletion of pressure makes the volume supply of gas to well rate easier than that of oil; therefore, the pressure drop of gas well production is lower than that of oil well production. Figure 9 also shows the difference between external boundary response time for oil and gas well production. A larger pressure drop for oil well production results in a faster propagation of pressure waves, therefore propagating time for a pressure wave to reach the closed external boundary for oil well production $\left(t_{\mathrm{eo}}\right)$ is shorter than that of gas well production $\left(t_{\mathrm{eg}}\right)$. According to the simulated results, external boundary response time of oil and gas flow is $0.6 \mathrm{~h}$ and $4.3 \mathrm{~h}$, respectively. As shown in Fig. 9, after a pressure wave reaches the closed external boundary, transient flow will reach a pseudo-steady state flow, in which the derivative curves converge to a straight line (Chaudhry, 2004; Nie et al., 2011a).

Table 5 lists partial data associated with the numerical simulation results and shows quantitative differences in numerical values among wellbore pseudo-pressure, wellbore pseudo-pressure drop, wellbore pressure and wellbore drop for both gas and oil well production under the same conditions. Differences in quantitative analyses can be described from the table: (1) pseudo-pressure values are near 1500 times that of pressure values. Therefore, comparisons between pseudo-pressure and pressure are not significant and comparisons of real wellbore pressure between gas and oil well production need to be calculated; (2) at the beginning of production, pressure drop in oil well production is about 19 times that of gas well production because a rate of $20 \mathrm{~m}^{3} \mathrm{~d}^{-1}$ is small for gas well production and high for oil well pro-

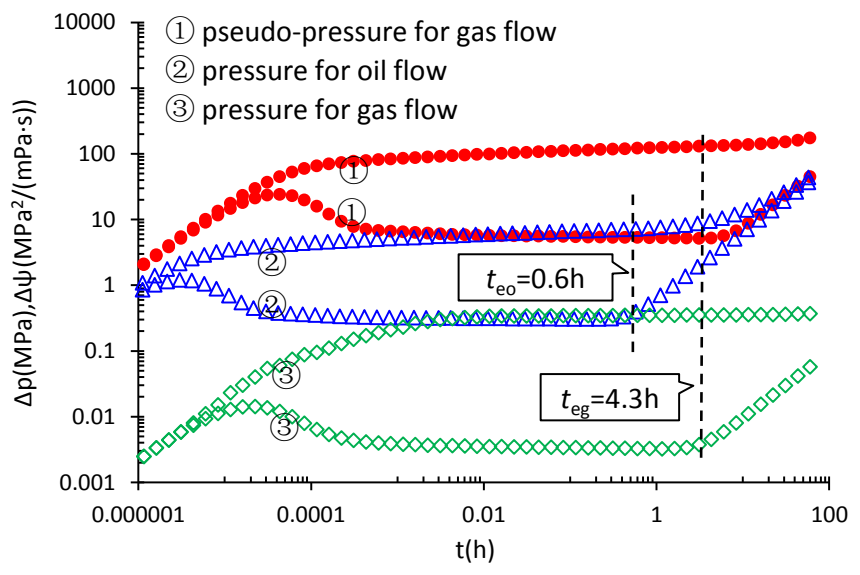

Fig. 9. Numerical solutions comparisons for oil and gas flows. For convenience, the same formation and well production conditions were used in the numerical simulations. Pseudo-pressure (see curve (1)) and pressure transients (see curves (3)) for gas well production, and pressure transients for oil well production (see curves (2)) were simulated. Pressure depletion of the oil well is greater than that of a gas well under the same conditions. For oil well production, propagating time of the pressure wave to the closed external boundary $\left(t_{\mathrm{eo}}\right)$ is approximately $0.6 \mathrm{~h}$. For gas well production, propagating time to the boundary $\left(t_{\text {eg }}\right)$ is about $4.3 \mathrm{~h}$.

duction in a formation with $10 \mathrm{~m}$ thickness; (3) at a time of " $t=0.6 \mathrm{~h}$ " when the pressure wave of oil well production reaches the external boundary, the pressure drop in the oil well is $7.21 \mathrm{MPa}$, while the pressure drop in the gas well is $0.346 \mathrm{MPa}$; (4) at the time of " $t=4.3 \mathrm{~h}$ " when the pressure wave of gas well production reaches the external boundary, the pressure drop of the gas well is $0.352 \mathrm{MPa}$, while the pressure drop in the oil well is $9.57 \mathrm{MPa}$; and (5) when the wellbore pressure of oil well production decreases to atmospheric pressure $(0.1 \mathrm{MPa})$, which is an absolute open flow status, the production time is $21.5 \mathrm{~h}$ which is the limit time of oil well at $20 \mathrm{~m}^{3} \mathrm{~d}^{-1}$ rate production. If production time exceeds limit time, the formation could not support an oil rate of $20 \mathrm{~m}^{3} \mathrm{~d}^{-1}$ and the rate must decline. However, at the limit time of oil well production the pressure drop of gas well production is only $0.358 \mathrm{MPa}$, which means the formation can easily support a gas rate of $20 \mathrm{~m}^{3} \mathrm{~d}^{-1}$ for an extended period of time.

In conclusion, numerical simulations show that there are obvious differences in wellbore pressure transients for oil and gas flow under the same formation and well conditions owing to the difference of fluid properties. Compared with gas wells, oil wells demand a relatively larger wellbore pressure drop and a relatively faster depletion. 
Table 5. Numerical comparisons between oil and gas well production.

\begin{tabular}{|c|c|c|c|c|c|c|}
\hline \multirow{2}{*}{$\begin{array}{c}t \\
(\mathrm{~h})\end{array}$} & \multicolumn{4}{|c|}{ gas well production } & \multicolumn{2}{|c|}{ oil well production } \\
\hline & $\begin{array}{c}\psi_{\mathrm{w}} \\
\mathrm{MPa}^{2}(\mathrm{mPas})^{-1}\end{array}$ & $\begin{array}{c}\Delta \psi \\
\mathrm{MPa}^{2}(\mathrm{mPas})^{-1}\end{array}$ & $\begin{array}{c}p_{\mathrm{W}} \\
(\mathrm{MPa})\end{array}$ & $\begin{array}{c}\Delta p \\
(\mathrm{MPa})\end{array}$ & $\begin{array}{c}p_{\mathrm{w}} \\
(\mathrm{MPa})\end{array}$ & $\begin{array}{c}\Delta p \\
(\mathrm{MPa})\end{array}$ \\
\hline 0 & 30630.13 & 0 & 20.50 & 0 & 20.50 & 0 \\
\hline 0.1 & 30519.08 & 111.05 & 20.157 & 0.343 & 13.87 & 6.63 \\
\hline 0.6 & 30509.25 & 120.88 & 20.154 & 0.346 & 13.29 & 7.21 \\
\hline 1 & 30506.78 & 123.35 & 20.152 & 0.348 & 12.99 & 7.51 \\
\hline 4.3 & 30498.56 & 131.57 & 20.148 & 0.352 & 10.93 & 9.57 \\
\hline 10 & 30493.71 & 136.42 & 20.146 & 0.354 & 7.64 & 12.86 \\
\hline 15 & 30490.52 & 139.61 & 20.145 & 0.355 & 4.58 & 15.92 \\
\hline 21.5 & 30485.67 & 144.46 & 20.142 & 0.358 & 0.1 & 20.50 \\
\hline
\end{tabular}

Explanations: $t$ is production time; $\psi_{\mathrm{W}}$ is gas pseudo-pressure of wellbore, $\mathrm{MPa}^{2}(\mathrm{mPas})^{-1} ; \Delta \psi$ is gas pseudo-pressure drop of wellbore, $\mathrm{MPa}^{2}(\mathrm{mPas})^{-1} ; p_{\mathrm{W}}$ is wellbore pressure; $\Delta p$ is wellbore pressure drop.

Table 6. Formation and well parameters of the example well.

\begin{tabular}{|c|c|c|c|c|c|c|c|c|c|}
\hline $\begin{array}{c}H_{\mathrm{t}} \sim H_{\mathrm{b}} \\
(\mathrm{m})\end{array}$ & $\begin{array}{c}h \\
(\mathrm{~m})\end{array}$ & $\Phi$ & $\begin{array}{c}C_{\rho} \\
\left(\mathrm{MPa}^{-1}\right)\end{array}$ & $\begin{array}{c}C_{\mathrm{t}} \\
\left(\mathrm{MPa}^{-1}\right)\end{array}$ & $\begin{array}{l}r_{\mathrm{W}} \\
(\mathrm{m})\end{array}$ & $\begin{array}{c}\mu \\
(\mathrm{mPas})\end{array}$ & $B$ & $\begin{array}{c}q \\
\left(\mathrm{~m}^{3} \mathrm{~d}^{-1}\right)\end{array}$ & $\begin{array}{l}t_{\mathrm{p}} \\
(\mathrm{h})\end{array}$ \\
\hline $1168 \sim 1171$ & 3 & 0.21 & 0.0034 & 0.0038 & 0.062 & 20.08 & 1.089 & 24.5 & 3465 \\
\hline
\end{tabular}

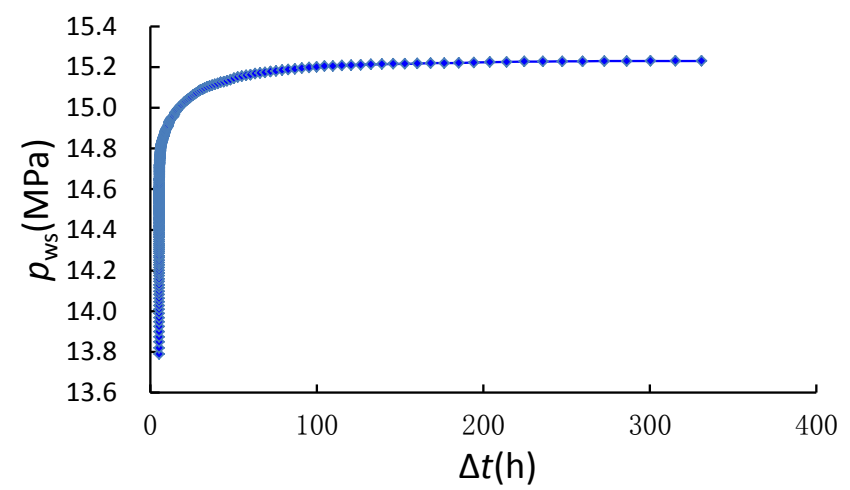

Fig. 10. Build-up pressure curve of well testing at wellbore of the example well. The relationship between build-up pressure and shutting-down time is shown. Wellbore pressure when shut down and at testing termination were $13.79 \mathrm{MPa}$ and $15.23 \mathrm{MPa}$, respectively. Shutting-down time of well testing was $326 \mathrm{~h}$.

\section{Field application}

This study used a pressure buildup testing well in a sandstone reservoir with an edge water drive. The curve of wellbore shutting-down pressure, $p_{\mathrm{ws}}$, with shutting-down time, $\Delta t$, is shown in Fig. 10. Formation and well parameters are shown in Table 6.

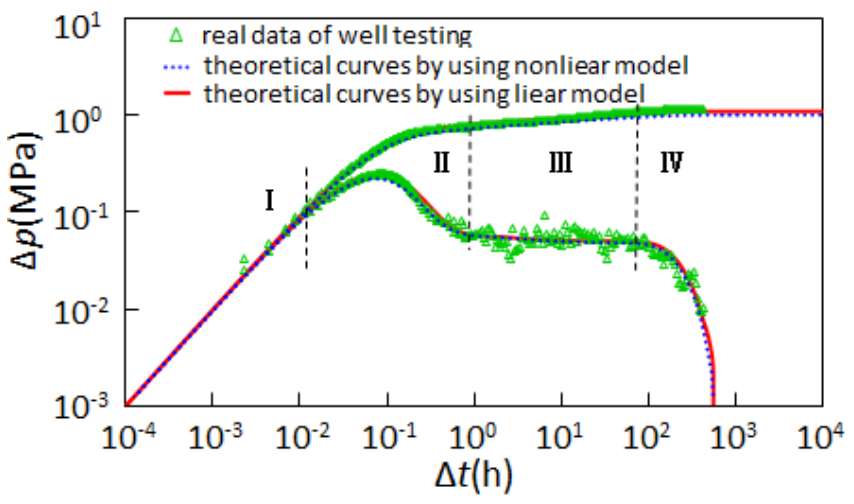

Fig. 11. Matching curves with units of well-test interpretation for the example well. Log-log curve characteristics of well-testing data and the matching effects of theoretical curves against actual testing data between the linear model and the nonlinear model are shown. Both models performed well. The matching effect of the derivative curves associated with the nonlinear model was more desirable, especially in Regimes II and IV.

Log-log curves of well-testing data are shown in Fig. 11. Four main flow regimes are observed: (i) Regime I, pure wellbore storage regime; (ii) Regime II, wellbore storage and skin effect regime; (iii) Regime III, radial flow regime; and (iv) Regime IV, external boundary response regime caused by edge water. 
The researched nonlinear flow model from this article was used to make a well-test interpretation. Matching curves from a well-testing interpretation using the nonlinear model with a constant pressure boundary are shown in Fig. 11. The conventional linear flow model with a constant pressure boundary was used in a well-test interpretation. Matching curves are shown in Fig. 11. Matching effects between the two interpretations are desirable. Differences between the theoretical curves and real testing data are noticeable (Fig. 11). Using the matching derivative curves, matching effects for the nonlinear model are more desirable than for the linear model, especially in periods II and IV. Matching curve differences between the two models were inconspicuous; therefore, the dimensionless matching curves of well-test interpretation were used to show the differences between the matching effects associated with the two models (Fig. 12).

The main interpretation parameters are shown in Table 7. The formation permeability $(k)$ of well-test interpretation using the nonlinear model is $0.03925 \mu \mathrm{m}^{2}$ and the dimensionless coefficient of nonlinear term $(\beta)$ of well-test interpretation using the nonlinear model is 0.0287 . We substituted the formation permeability value $\left(0.03925 \mu \mathrm{m}^{2}\right)$ into the equation $\beta=\left(1.842 \times 10^{-3} q B \mu C_{\rho}\right) /(k h)$ and calculated $\beta$. The calculated value of $\beta$ using interpretation permeability $=0.0285$, which is slightly smaller than the interpretation $\beta$ value (0.0287). The differential value and the relative differential value are 0.0003 and $0.70 \%$, respectively. Therefore, interpretation results using a nonlinear flow model are credible and there is no need to re-match field testing data by changing theoretical parameters.

Table 7 shows the obvious differences between well-test interpretation parameter values for the two models. The differential value of the wellbore storage coefficient is zero because wellbore pressure of the example well is not affected by nonlinearity of oil flow in the wellbore storage regime (Table 7). The values of parameters $S, k$, and $r_{\mathrm{e}}$ using nonlinear model interpretation are smaller than those using nonlinear model interpretations. The relative differential value of $S, k$ and $r_{\mathrm{e}}$ are $29.63 \%, 18.53 \%$, and $10.38 \%$, respectively.

Interpretation using the conventional linear flow model would enlarge the parameter value. The nonlinear flow model is recommended because it is a useful tool for evaluation of formation properties and prediction of engineering conditions.

\section{Conclusions}

Nonlinear diffusion equations of liquid and gas in porous media were deduced, nonlinear flow models were established and solved and nonlinear flow behaviour was simulated and analyzed. The findings are as follows:

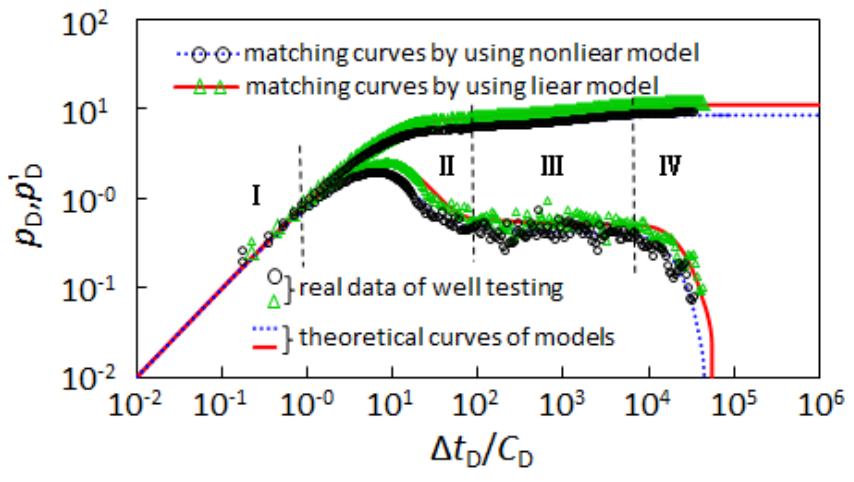

Fig. 12. Dimensionless matching curves of well-test interpretation for the example well. The dimensionless matching curves were used to show differences between well-test analyses using nonlinear and linear models. Obvious differences in the theoretical type curves were found.

Table 7. Main interpretation parameters of the example well.

\begin{tabular}{cccccc}
\hline model & $\begin{array}{c}C_{\mathrm{S}} \\
\left(\mathrm{m}^{3} \mathrm{MPa}^{-1}\right)\end{array}$ & $S$ & $\begin{array}{c}k \\
\left(10^{-3} \mu \mathrm{m}^{2}\right)\end{array}$ & $\begin{array}{c}r_{\mathrm{e}} \\
(\mathrm{m})\end{array}$ & $\beta$ \\
\hline nonlinear & 0.0062 & 0.57 & 39.25 & 561 & 0.0287 \\
linear & 0.0062 & 0.81 & 48.18 & 626 & - \\
DV & 0 & 0.24 & 8.93 & 65 & - \\
RDV $(\%)$ & 0 & 29.63 & 18.53 & 10.38 & - \\
\hline
\end{tabular}

Explanations: $C_{\mathrm{S}}$ is wellbore storage coefficient; $S$ is skin factor; $k$ is formation permeability; $r_{\mathrm{e}}$ is distance of constant pressure boundary from wellbore; $\beta$ is dimensionless coefficient of nonlinear term; DV is differential value; RDV is relative differential value.

1. Effects of nonlinearity upon pressure transients are obvious and nonlinear models more accurately portrait the flow processes of fluid in porous media.

2. Locations of pressure and nonlinear model derivative curves for liquid flow are lower than those derived from linear models.

3. Differences between nonlinear and linear model pressure transients increase with time and the nonlinear coefficient.

4. Influences of nonlinearity are greater for formations with low permeability, heavy oil or thin thickness.

5. Nonlinear transient flow behaviour of gas is different from that of oil because of dissimilar fluid properties. 


\section{Appendix A}

The material balance equation for liquid flow in porous media reservoirs can be expressed as

$\frac{\partial}{\partial x}\left(\rho v_{x}\right)+\frac{\partial}{\partial y}\left(\rho v_{y}\right)+\frac{\partial}{\partial z}\left(\rho v_{z}\right)=-\frac{\partial}{\partial t}(\rho \varphi)$,

where $\rho$ is density, $\mathrm{g} \mathrm{cm}^{-3} ; \varphi$ is rock porosity, fraction; $t$ is time, $\mathrm{s} ; x, y$, and $z$ are Cartesian coordinates; $v_{x}$ is flow velocity in the $x$ direction, $\mathrm{cms}^{-1} ; v_{y}$ is flow velocity in the $y$ direction, $\mathrm{cms}^{-1} ; v_{z}$ is flow velocity in the $z$ direction, $\mathrm{cms}^{-1}$.

Considering isothermal equations and Darcy's flow, the motion equation of liquid can be expressed as

$v=-0.1 \frac{k_{j}}{\mu} \nabla p, \quad(j=x, y, z)$,

where $p$ is pressure, $\mathrm{MPa} ; \mu$ is viscosity, $\mathrm{mPas} ; v$ is flow velocity, $\mathrm{cms}^{-1} ; k_{x}$ is permeability in the $x$ direction, $\mu \mathrm{m}^{2}$; $k_{y}$ is permeability in the $y$ direction, $\mu \mathrm{m}^{2} ; k_{z}$ is permeability in the $z$ direction, $\mu \mathrm{m}^{2}$.

Substitute Eq. (A2) into Eq. (A1):

$\frac{\partial}{\partial x}\left(\rho \frac{k_{x}}{\mu} \frac{\partial p}{\partial x}\right)+\frac{\partial}{\partial y}\left(\rho \frac{k_{y}}{\mu} \frac{\partial p}{\partial y}\right)+\frac{\partial}{\partial z}\left(\rho \frac{k_{z}}{\mu} \frac{\partial p}{\partial z}\right)=10 \frac{\partial}{\partial t}(\rho \varphi)$,

$\frac{\partial}{\partial x}\left(\rho \frac{k_{x}}{\mu} \frac{\partial p}{\partial x}\right)=\frac{\rho k_{x}}{\mu} \frac{\partial^{2} p}{\partial x^{2}}+\frac{\rho}{\mu} \frac{\partial p}{\partial x} \frac{\partial k_{x}}{\partial x}+\frac{k_{x}}{\mu} \frac{\partial p}{\partial x} \frac{\partial \rho}{\partial x}$

Change the form of Eq. (3):

$p=\frac{1}{C_{\rho}} \ln \rho-\frac{1}{C_{\rho}} \ln \rho_{0}+p_{0}$,

$\frac{\partial p}{\partial x}=\frac{1}{\rho C_{\rho}} \frac{\partial \rho}{\partial x}$

$\frac{\partial p}{\partial t}=\frac{1}{\rho C_{\rho}} \frac{\partial \rho}{\partial t}$

where $C_{\rho}$ is liquid compressibility, $\mathrm{MPa}^{-1} ; \rho_{0}, \varphi_{0}, p_{0}$ are reference values, which are usually used under standard conditions.

Substitute Eq. (A6) into Eq. (A4):

$\frac{\partial}{\partial x}\left(\rho \frac{k_{x}}{\mu} \frac{\partial p}{\partial x}\right)=\frac{\rho k_{x}}{\mu} \frac{\partial^{2} p}{\partial x^{2}}+\frac{\rho}{\mu} \frac{\partial p}{\partial x} \frac{\partial k_{x}}{\partial x}+\frac{k_{x} \rho C_{\rho}}{\mu}\left(\frac{\partial p}{\partial x}\right)^{2}$.

By the same method, the following two equations can be deduced:

$\frac{\partial}{\partial y}\left(\rho \frac{k_{y}}{\mu} \frac{\partial p}{\partial y}\right)=\frac{\rho k_{y}}{\mu} \frac{\partial^{2} p}{\partial y^{2}}+\frac{\rho}{\mu} \frac{\partial p}{\partial y} \frac{\partial k_{y}}{\partial y}+\frac{k_{y} \rho C_{\rho}}{\mu}\left(\frac{\partial p}{\partial y}\right)^{2}$, $\frac{\partial}{\partial z}\left(\rho \frac{k_{z}}{\mu} \frac{\partial p}{\partial z}\right)=\frac{\rho k_{z}}{\mu} \frac{\partial^{2} p}{\partial z^{2}}+\frac{\rho}{\mu} \frac{\partial p}{\partial z} \frac{\partial k_{z}}{\partial z}+\frac{k_{z} \rho C_{\rho}}{\mu}\left(\frac{\partial p}{\partial z}\right)^{2}$.

Change the form of Eq. (4):

$p=\frac{1}{C_{\mathrm{f}}} \ln \varphi-\frac{1}{C_{\mathrm{f}}} \ln \varphi_{0}+p_{0}$,

$\frac{\partial p}{\partial t}=\frac{1}{\varphi C_{\mathrm{f}}} \frac{\partial \varphi}{\partial t}$,

where $C_{\mathrm{f}}$ is rock compressibility, $\mathrm{MPa}^{-1}$.

Substitute Eqs. (A12) and (A7) into Eq. (A3), the right of Eq. (A3) is changed as

$\frac{\partial}{\partial t}(\rho \varphi)=\varphi \frac{\partial \rho}{\partial t}+\rho \frac{\partial \varphi}{\partial t}=\rho \varphi C_{\rho} \frac{\partial p}{\partial t}+\rho \varphi C_{\mathrm{f}} \frac{\partial p}{\partial t}=\rho \varphi C_{\mathrm{t}} \frac{\partial p}{\partial t}$,

$C_{\mathrm{t}}=C_{\rho}+C_{\mathrm{f}}$

where $C_{\mathrm{t}}$ is total compressibility of rock and liquid, $\mathrm{MPa}^{-1}$.

Substitute Eqs. (A8)-(A10) and Eq. (A13) into Eq. (A.3):

$$
\begin{aligned}
& \left(k_{x} \frac{\partial^{2} p}{\partial x^{2}}+k_{y} \frac{\partial^{2} p}{\partial y^{2}}+k_{z} \frac{\partial^{2} p}{\partial z^{2}}\right)+\left(\frac{\partial p}{\partial x} \frac{\partial k_{x}}{\partial x}+\frac{\partial p}{\partial y} \frac{\partial k_{y}}{\partial y}+\frac{\partial p}{\partial z} \frac{\partial k_{z}}{\partial z}\right) \\
& +C_{\rho}\left[k_{x}\left(\frac{\partial p}{\partial x}\right)^{2}+k_{y}\left(\frac{\partial p}{\partial y}\right)^{2}+k_{z}\left(\frac{\partial p}{\partial z}\right)^{2}\right] \\
& =10 \mu \varphi C_{t} \frac{\partial p}{\partial t} .
\end{aligned}
$$

We assume the permeability in both the horizontal and vertical planes is isotropic and constant:

$k_{x}=k_{y}=k_{\mathrm{h}}$,

$\frac{\partial k_{x}}{\partial x}=\frac{\partial k_{y}}{\partial y}=\frac{\partial k_{z}}{\partial z}=0$,

where $k_{\mathrm{h}}$ is permeability in the horizontal plane, $\mu \mathrm{m}^{2}$.

Substitute Eqs. (A16) and (A17) into Eq. (A15):

$$
\begin{aligned}
& \left(\frac{\partial^{2} p}{\partial x^{2}}+\frac{\partial^{2} p}{\partial y^{2}}+\frac{k_{z}}{k_{\mathrm{h}}} \frac{\partial^{2} p}{\partial z^{2}}\right)+C_{\rho}\left[\left(\frac{\partial p}{\partial x}\right)^{2}+\left(\frac{\partial p}{\partial y}\right)^{2}+\frac{k_{z}}{k_{\mathrm{h}}}\left(\frac{\partial p}{\partial z}\right)^{2}\right] \\
& =\frac{10 \mu \varphi C_{\mathrm{t}}}{k_{\mathrm{h}}} \frac{\partial p}{\partial t} .
\end{aligned}
$$

Equation (A19) is the governing differential equation containing the quadratic gradient term in Cartesian coordinates. 
Acknowledgements. The authors would like to thank the central government of China and the Southwest Petroleum University (SWPU) for supporting this article through a special fund of China's central government for the development of local colleges and universities - the project of national first-level discipline in Oil and Gas Engineering. The authors would like to also thank the reviewers (Sid-Ali Ouadfeul, Simon L. Marshall et al.) and the editors (Leila Alioune et al.) for their careful and critical reviews.

Edited by: L. Aliouane

Reviewed by: S. Marshall and S.-A. Ouadfeul

\section{References}

Agarwal, R. G., Al-Hussainy, R., and Ramey Jr., H. J.: An investigation of wellbore storage and skin effect in unsteady liquid flow: I. Analytical Treatment, SPE Journal, 10, 279-290, doi:10.2118/2466-PA, 1970.

Bai, M. and Roegiers, J. C.: On the correlation of nonlinear flow and linear transport with application to dual-porosity modeling, J. Petrol. Sci. Eng., 11, 63-72, doi:0.1016/0920-4105(94)900299, 1994.

Bai, M., Ma, Q., and Roegiers, J. C.: A nonlinear dual porosity model, Appl. Math. Model., 18, 602-610, doi:10.1016/0307904X(94)90318-2, 1994.

Braeuning, S., Jelmert, T. A., and Vik, S. A.: The effect of the quadratic gradient term on variable-rate well-tests, J. Petrol. Sci. Eng., 21, 203-222, doi:10.1016/S0920-4105(98)00073-4, 1998.

Cao, X. L., Tong, D. K., and Wang, R. H.: Exact solutions for nonlinear transient flow model including a quadratic gradient term, Appl. Math. Mech.-Engl., 25, 102-109, doi:10.1007/BF02437298, 2004.

Chakrabarty, C., Ali, S. M. F., and Tortike, W. S.: Analytical solutions for radial pressure distribution including the effects of the quadratic gradient term, Water Resour. Res., 29, 1171-1177, doi:10.1029/92WR02892, 1993a.

Chakrabarty, C., Ali, S. M. F., and Tortike, W. S.: Effects of the nonlinear gradient term on the transient pressure solution for a radial flow system, J. Petrol. Sci. Eng., 8, 241-256, doi:10.1016/09204105(93)90002-V, 1993b.

Chaudhry, A. U.: Oil Well-testing Handbook, Gulf Professional Publishing, Oxford, UK, p. 161, 2004.

Corbett, P. W. M., Geiger, S., Borges, L., Garayev, M., and Valdez, C.: The third porosity system: understanding the role of hidden pore systems in well-test interpretation in carbonates, Petrol. Geosci., 18, 73-81, doi:10.1144/1354-079311-010, 2012.

Ertekin, T. and Sung, W.: Pressure transient analysis of coal seams in the presence of multi-mechanistic flow and sorption phenomena, Paper SPE 19102, presented at: the SPE Gas Technology Symposium, Dallas, Texas, 7-9 June, doi:10.2118/19102-MS, 1989.

Finjord, J.: A solitary wave in a porous medium, Transport Porous Med., 5, 591-607, doi:10.1007/BF00203330, 1990.

Finjord, J. and Aadnoy, B. S.: Effects of the quadratic gradient term in steady-state and semisteady-state solutions for reservoir pressure, SPE Formation Eval., 4, 413-417, doi:10.2118/15969-PA, 1989.
Giachetti, D. and Maroscia, G.: Existence results for a class of porous medium type equations with a quadratic gradient term, J. Evol. Equ., 8, 155-188, doi:10.1007/s00028-007-0362-3, 2008.

Hagoort, J.: Fundamentals of Gas Reservoir Engineering, Elsevier Science, Amsterdam, p. 27, 1988.

Jelmert, T. A. and Vik, S. A.: Analytic solution to the non-linear diffusion equation for fluids of constant compressibility, J. Petrol. Sci. Eng., 14, 231-233, doi:10.1016/0920-4105(95)00050-X, 1996.

King, G. R. and Ertekin, T.: Comparative evaluation of vertical and horizontal drainage wells for the degasification of coal seams, SPE Reservoir Eng., 3, 720-734, doi:10.2118/13091-PA, 1988.

Liang, Y., Price, J. D., Wark, D. A., and Watson, E. B.: Nonlinear pressure diffusion in a porous medium: Approximate solutions with applications to permeability measurements using transient pulse decay method, J. Geophys. Res., 106, 529-535, doi:10.1029/2000JB900344, 2001.

Marshall, S. L.: Nonlinear pressure diffusion in flow of compressible liquids through porous media, Transport Porous Med., 77, 431-446, doi:10.1007/s11242-008-9275-z, 2009.

Nie, R., Meng, Y., Yang, Z., Guo, J., and Jia, Y.: New flow model for the triple media carbonate reservoir, Int. J. Comput. Fluid D., 25, 95-103, doi:10.1080/10618562.2011.560573, $2011 \mathrm{~b}$.

Nie, R. S. and Ding, Y.: Research on the nonlinear spherical percolation model with quadratic pressure gradient and its percolation characteristics, Natural Science, 2, 98-105, doi:10.4236/ns.2010.22016, 2010.

Nie, R. S., Guo, J. C., Jia, Y. L., Zhu, S. Q., Rao, Z., and Zhang, C. G.: New modelling of transient well-test and rate decline analysis for a horizontal well in a multiple-zone reservoir, J. Geophys. Eng., 8, 464-467, doi:10.1088/1742-2132/8/3/007, 2011a.

Nie, R. S., Meng, Y. F., Guo, J. C., and Jia, Y. L.: Modeling transient flow behavior of a horizontal well in a coal seam, Int. J. Coal Geol., 92, 54-68, doi:10.1016/j.coal.2011.12.005, 2012a.

Nie, R. S., Meng, Y. F., Jia, Y. L., Zhang, F. X., Yang, X.T., and Niu, X. N.: Dual porosity and dual permeability modeling of horizontal well in naturally fractured reservoir, Transport Porous Med., 92, 213-235, doi:10.1007/s11242-011-9898-3, 2012b.

Nie, R. S., Meng, Y. F., Jia, Y. L., Shang, J. L., Wang, Y., and Li, J. G.: Unsteady inter-porosity flow modeling for a multiple media reservoir, Acta Geophys., 60, 232-259, doi:10.2478/s11600011-0053-x, 2012c.

Odeh, A. S. and Babu, D. K.: Comprising of solutions for the nonlinear and linearized diffusion equations, SPE Reservoir Eng., 3, 1202-1206, doi:10.2118/17270-PA, 1998.

Onur, M., Zeybek, A. D., Serpen, U., and Gok, I. M.: Application of modern well-test analysis techniques to pressure transient tests in Kizildere geothermal field, Turkey, Geothermics, 32, 147-170, doi:10.1016/S0375-6505(02)00068-8, 2003.

Stehfest, H.: Numerical inversion of Laplace transform - algorithm 368, Communication of the ACM, 13, 47-49, 1970.

Tong, D. K. and Wang, R. H.: Exact solutions of pressure transient model for fluid flow in fractal reservoir including a quadratic gradient term, Energ. Sour. Part A, 27, 1205-1215, doi:10.1080/009083190519168, 2005.

Wang, Y. and Dusseault, M.: The effect of quadratic gradient terms on the borehole solution in poroelastic media, Water Resour. Res., 27, 3215-3223, doi:10.1029/91WR01552, 1991. 